\title{
Characterization of the organic composition of aerosols from Rondônia, Brazil, during the LBA-SMOCC 2002 experiment and its representation through model compounds
}

\author{
S. Decesari ${ }^{1}$, S. Fuzzi ${ }^{1}$, M. C. Facchini ${ }^{1}$, M. Mircea ${ }^{1}$, L. Emblico ${ }^{1}$, F. Cavalli ${ }^{1}$, W. Maenhaut ${ }^{2}$, X. Chi ${ }^{2}$, G. Schkolnik ${ }^{3}$, \\ A. Falkovich ${ }^{3}$, Y. Rudich ${ }^{3}$, M. Claeys ${ }^{4}$, V. Pashynska ${ }^{4}$, G. Vas $^{4}$, I. Kourtchev ${ }^{4}$, R. Vermeylen ${ }^{4}$, A. Hoffer ${ }^{5}$, \\ M. O. Andreae ${ }^{5}$, E. Tagliavini ${ }^{6,7}$, F. Moretti ${ }^{6}$, and P. Artaxo ${ }^{8}$ \\ ${ }^{1}$ Istituto Scienze dell'Atmosfera e del Clima - C.N.R., Bologna, Italy \\ ${ }^{2}$ Department of Analytical Chemistry, Institute for Nuclear Sciences, Ghent University, Gent, Belgium \\ ${ }^{3}$ Department of Environmental Sciences, Weizmann Institute, Rehovot, Israel \\ ${ }^{4}$ Department of Pharmaceutical Sciences, University of Antwerp, Antwerp, Belgium \\ ${ }^{5}$ Biogeochemistry Department, Max Planck Institute for Chemistry, Mainz, Germany \\ ${ }^{6}$ Dipartimento di Chimica “G. Ciamician”, Università di Bologna, Bologna, Italy \\ ${ }^{7}$ Centro di Ricerche per le Scienze Ambientali, Università di Bologna, Ravenna, Italy \\ ${ }^{8}$ Instituto de Fisica, Universidade de Sao Paulo, Sao Paulo, SP, Brazil
}

Received: 2 May 2005 - Published in Atmos. Chem. Phys. Discuss.: 9 August 2005

Revised: 28 November 2005 - Accepted: 27 December 2005 - Published: 7 February 2006

\begin{abstract}
The chemical composition of carbonaceous aerosols collected during the LBA-SMOCC field experiment, conducted in Rondônia, Brazil, in 2002 during the transition from the dry to the wet season, was investigated by a suite of state-of-the-art analytical techniques. The period of most intense biomass burning was characterized by high concentrations of submicron particles rich in carbonaceous material and water-soluble organic compounds (WSOC). At the onset of the rainy period, submicron total carbon (TC) concentrations decreased by about 20 times. In contrast, the concentration of supermicron TC was fairly constant throughout the experiment, pointing to a constant emission of coarse particles from the natural background. About $6-8 \%$ of TC (9-11\% of WSOC) was speciated at the molecular level by GC-MS and liquid chromatography. Polyhydroxylated compounds, aliphatic and aromatic acids were the main classes of compounds accounted for by individual compound analysis. Functional group analysis by proton NMR and chromatographic separation on ion-exchange columns allowed characterization of ca. $50-90 \%$ of WSOC into broad chemical classes (neutral species/light acids/humic-like substances). In spite of the significant change in the chemical composition of tracer compounds from the dry to the wet period, the functional groups and the general chemical classes of WSOC changed only to a small extent. Model compounds representing size-resolved WSOC chemical composition for
\end{abstract}

Correspondence to: S. Decesari

(s.decesari@isac.cnr.it) the different periods of the campaign are then proposed in this paper, based on the chemical characterization by both individual compound analysis and functional group analysis deployed during the LBA-SMOCC experiment. Model compounds reproduce quantitatively the average chemical structure of WSOC and can be used as best-guess surrogates in microphysical models involving organic aerosol particles over tropical areas affected by biomass burning.

\section{Introduction}

The Large Scale Biosphere-Atmosphere Experiment in Amazonia - Smoke, Aerosols, Clouds, Rainfall and Climate (LBA-SMOCC) experiment was conducted in the Amazon Basin in the period September - mid-November 2002, with the principal purpose of investigating how and to what extent aerosol particles produced by biomass burning alter cloud formation. Previous studies have highlighted that smoke particles emitted by biomass burning are enriched in organic carbon (OC) and also contain a variable amount of elemental carbon (EC), operationally defined as the fraction of carbon that is refractory at high temperature in an inert atmosphere (Chow et al., 2001; Mayol-Bracero et al., 2002a, b). Elemental carbon is often used as a synonym for "soot carbon" defined by $\operatorname{IPCC}(2001)$ as "Particles formed during the quenching of gases at the outer edge of flames of organic vapors, consisting predominantly of carbon, with lesser

(C) 2006 Author(s). This work is licensed under a Creative Commons License. 
amounts of oxygen and hydrogen present as carboxyl and phenolic groups and exhibiting an imperfect graphitic structure".

Although carbonaceous aerosols are less hygroscopic than particles consisting of sulfate or sodium chloride, the polar organic compounds known to occur in biomass burning aerosol may absorb water from the gas phase, thus enhancing the ability to nucleate cloud droplets ("CCN ability") of the particles (Svenningsson et al., 2005). The organic compounds that have an affinity to water are generally isolated by extracting aerosol samples with water and measuring their total carbon concentration by liquid total organic carbon (TOC) analysis. These water-soluble organic compounds (WSOC) constitute a variable fraction of the aerosol TC. They can be internally or externally mixed with other aerosol constituents (e.g., inorganic soluble and insoluble components) and, most importantly, they contain a wide range of chemical species that are expected to show very different water solubilities (Mochida and Kawamura, 2004). All these factors are of primary importance in determining the $\mathrm{CCN}$ ability of biomass burning particles.

In order to evaluate the net effect of carbonaceous particles from biomass burning on the formation of clouds, it is indicated to compare their characteristics with those formed during unpolluted episodes in the same region. The SMOCC aircraft campaign revealed that forested areas distant from the biomass burning sources show a background of $\mathrm{CCN}$ with low concentrations and a rather constant vertical profile in the troposphere (Andreae et al., 2004). Previous studies highlighted the occurrence of natural sources of aerosol particles from the biota in the same area (Graham et al., 2003). The processes responsible for particle formation in the Amazon basin - biomass burning and biogenic emission - are geographically distinct and follow very different temporal trends. In particular, the dramatic increase in the aerosol load observed during the dry period in the rural areas of Rondônia and Mato Grosso can be mainly attributed to biomass burning. In the same period, biomass burning products strongly impact the TC concentrations and composition in the neighboring forested areas. Biogenic organic aerosols have mainly been characterized at forest sites located at a large distance from the main pollution sources (Kubátová et al., 2000; Graham et al., 2003; Claeys et al., 2004a). However, primary biological particles (e.g., pollen and fungal spores) were found to increase also in rural areas at the end of the dry period, when the increase in precipitation impedes extensive burning activities (Graham et al., 2002).

The chemical composition of carbonaceous particles produced by biomass burning in Rondônia was characterized during the 1999 LBA-EUSTACH-2 campaign (MayolBracero et al., 2002a). It was found that WSOC account for $45-75 \%$ of TC and that a substantial fraction of the thermally refractory carbon determined by evolved gas analysis (EGA) analysis is also water-soluble. This soluble refractory carbonaceous material was linked to complex poly- carboxylic acids, which are denoted by the generic term "HULIS" (humic-like substances) and were determined by analysis of water extracts. Another important fraction of WSOC was identified as neutral compounds mainly consisting of sugar-like compounds such as levoglucosan, which is the most abundant product of the pyrolysis of cellulose at temperatures higher than $300^{\circ} \mathrm{C}$ (Shafizadeh, 1984).

Except for levoglucosan, linking the organic composition of the aerosol to the chemical reactions occurring during the complex and varying combustion processes remains an issue. The relatively low concentrations of sugars in biomass burning smoke, compared to the abundance of their degradation products, likely results from the fact that biomolecules undergo pronounced chemical transformations, even at relatively low temperatures $\left(<200^{\circ} \mathrm{C}\right)$, owing to heterogeneous reactions with oxygen and reactions between amines and sugars (Moens et al., 2004). Combustion studies on Graminaceae (Knicker et al., 1996) have shown that at $350^{\circ} \mathrm{C}$ cellulose and hemicelluloses are completely degraded to volatile products (with levoglucosan as a major compound) in a time span of $1 \mathrm{~min}$. The remaining char products contain mainly complex aliphatic compounds and newly formed aromatic compounds, and have a very low content of oxygenated substances. The composition of these char residues is completely different from that of biomass burning aerosol which instead shows a large fraction of oxygenated compounds (Graham et al., 2002). The oxygenated compounds may form during the low-temperature stages of combustion. In addition, a substantial fraction of compounds volatilized at the high temperatures of the combustion process may condense onto particles, when the smoke plume cools down. Finally, photochemical production of newly formed condensable compounds within the plume and in the regional haze will increase the fraction of oxygenated species relative to soot (Gao et al., 2003; Reid et al., 2005). Therefore, there are a number of processes that are responsible for the high content of oxygenated water-soluble organic compounds in biomass burning particles, ranging from combustion itself, through the early aging stages to actual in-situ secondary processes. Chemical transformation within the aerosol particles, e.g., polymerization of low-molecular weight compounds, is not a likely mechanism for altering significantly the oxygen to carbon ratio of the organic matter. However, it may alter its solubility through the modification of functional groups of specific classes of compounds, for example, benzoic acids may be converted to high-molecular weight aromatic acids (Hoffer et al., 2005) and unsaturated acids may be further oxidized to dihydroxy acid derivatives (Claeys et al., 2004b).

The biogenic sources of organic aerosols are still only partly understood and cover a wide range of different sources and source processes. The identification of biomolecules (mainly sugars and lipids) in the coarse fraction of aerosols collected at forest sites has highlighted the importance of the direct emission of primary biological particles, like spores, pollen, plant debris, soil detritus and insect body parts, to 
the atmosphere (Graham et al., 2003; Simoneit et al., 2004). Recently, another source process has been characterized for the formation of secondary organic aerosols, i.e., photooxidation of isoprene which is emitted in large amounts by the tropical forest vegetation (Claeys et al., 2004a; Wang et al., 2005).

Biomass burning and biogenic sources show a very different seasonal dependence. In a simplified scheme (since the Amazon forest ecosystem is productive throughout the year, while biomass burning mainly occurs in the dry period), the latter gives rise to episodes of very high aerosol loads, which are superimposed on a relatively constant natural background of primary biological particles and photooxidation products of biogenic volatile organic compounds (secondary organic aerosol). Consequently, the atmospheric concentrations of biomass burning aerosols, along with their composition, will vary according to the strength and type of the combustion sources, as well as the ambient conditions, with strong diel and day-to-day variations (Falkovich et al., 2005; Schkolnik et al., 2005; Fuzzi et al., 2006 ${ }^{1}$ ). The aim of this study is to trace the changes in the organic aerosol composition during the transition from the biomass burning period to the rainy period, with particular focus on WSOC. A combination of state-of-the-art techniques for speciation of polar organic compounds has been exploited for the chemical characterization, together with functional group analysis by ${ }^{1} \mathrm{HNMR}$. The results and implications of some specific analytical methods have been published in separate papers (Falkovich et al., 2005; Schkolnik et al., 2005). Here, they are included to provide comprehensive compositions for the main periods of the LBA-SMOCC field campaign. In past studies on tropical areas affected by biomass burning, only limited analyses (e.g., ion chromatography or GC-MS) on selected samples have been performed, providing sets of measurements that are difficult to intercompare (Reid et al., 2005). Here, we provide what is probably the most complete set of analyses of biomass burning aerosols, for a full assessment of the organic chemical composition. Finally, we propose a model representation of the water-soluble fraction of OC, derived from both individual compounds and functional group composition for the different periods of the campaign. These model compositions should be useful in microphysical models of aerosol hygroscopic growth, as well as in laboratory studies for the determination of the hygroscopic behav-

\footnotetext{
${ }^{1}$ Fuzzi, S., Decesari, S., Facchini, M. C., Cavalli, F., Emblico, L., Mircea, M., Andreae, M. O., Trebs, I., Hoffer, A., Guyon, P., Artaxo, P., Rizzo, L.V., Lara, L. L., Pauliquevis, T., Maenhaut, W., Raes, N., Chi, X., Mayol-Bracero, O. L., Soto, L., Claeys, M., Kourtchev, I., Rissler, J., Swietlicki, E., Tagliavini, E., Schkolnik, G., Falkovich, A. H., Rudich, Y., Fisch G., and Gatti, L. V.: Overview of the inorganic and organic composition of sizesegregated aerosol in Rondônia, Brazil, from the biomass burning period to the onset of the wet season, J. Geophys. Res., in review, 2006.
}

ior of mixed organic/inorganic systems (Svenningsson et al., 2005).

\section{Experimental}

\subsection{Sampling}

The SMOCC field campaign was conducted at a groundbased station on the Fazenda Nossa Senhora Aparecida (FNS) $\left(10^{\circ} 45^{\prime} 44^{\prime \prime} \mathrm{S}, 62^{\circ} 21^{\prime} 27^{\prime \prime} \mathrm{W}, 315 \mathrm{~m}\right.$ a.s.l.), which is located approximately $8 \mathrm{~km}$ southwest of the town Ouro Preto do Oeste in the state of Rondônia, Brazil. The place was deforested by fire about 20 years ago and the area is now a pasture site with Brachiaria brizantha as a dominant grass species. Sampling of aerosol particles was conducted from 9 September to 14 November 2002, by deploying a series of impactors and filter-based techniques. A full description of the sampling platform is provided by Fuzzi et al. $\left(2006^{1}\right)$. According to meteorological conditions, the sampling period was subdivided into dry (intense burning; 11 September to 7 October), transition (8 October to 29 October) and wet (30 October to 14 November) periods. With respect to the determination of total carbon (TC) and organic and elemental carbon (OC and EC), and of the organic chemical composition, sampling was conducted with: a) a stacked filter unit (SFU) sampler that separates coarse $(10>d>2.0 \mu \mathrm{m}$, where $d$ is the aerodynamic diameter) and fine particles $(d<2.0 \mu \mathrm{m})$ by sequential filtration on 8.0 and $0.4 \mu \mathrm{m}$ pore-size Nuclepore ${ }^{\circledR}$ polycarbonate filters, with a flow rate of $10-151 / \mathrm{min}$, operated by the Institute of Physics of the University of Sao Paulo (IFUSP); b) two SFU samplers equipped with quartz fiber filters (front and back-up) with a flow rate of 171/min and $\mathrm{PM}_{10}$ and $\mathrm{PM}_{2.5}$ inlets, respectively, both operated by Ghent University (UGent); c) three high-volume dichotomous impactors (HVDS) with front and back quartz fiber filters, segregating fine (PM2.5) and coarse $(>2.5 \mu \mathrm{m})$ particles, operating at a flow rate of ca. $300 \mathrm{l} / \mathrm{min}$, and deployed by UGent (HVDS1 $1_{\text {UGent }}$ and HVDS2 $2_{\text {UGent }}$ ) and by the Max Planck Institute for Chemistry (MPIC) (HVDS MPIC); d) two microorifice uniform deposit impactors (MOUDI IFUSP, from the University of Sao Paulo) with Nuclepore ${ }^{\circledR}$ polycarbonate filters

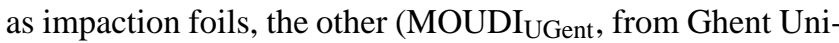
versity) with aluminum foils on the impaction stages; e) a 5-stage Berner impactor with aluminum and Tedlar foils on the impaction stages, deployed by ISAC (Istituto Scienze dell'Atmosfera e del Clima). Sampling time varied from $12 \mathrm{~h}$ in the dry period (when the highest aerosol concentrations were encountered) to 24 and $48 \mathrm{~h}$ at the end of the campaign. Positive artifacts during sampling were either avoided by using inert substrates (polycarbonate, Tedlar, Aluminum) or corrected by the analysis of back-filters (in the case of quartz filters). In contrast, presumably semi-volatile organic compounds (Eatough et al., 2003) could not be efficiently collected by our sampling apparatus. 
The comparison of aerosol measurements performed with analogous sampling systems (e.g., HVDS and SFU) indicates that the uncertainties in the flow measurement and potential other minor sampling biases, such as differences in the size cutoff between samples, led to differences of up to $25 \%$ in the concentration data reported from the various samplers and groups. Where such biases could be quantified and corrections applied, this is indicated in the text and tables. Otherwise, values are reported as obtained from the species mass measured on the particular samples and the sample volumes determined with the flow meters attached to the individual samplers.

\section{$2.2 \mathrm{TC} / \mathrm{OC} / \mathrm{EC}$ analysis}

Ghent University (UGent) analyzed the $\mathrm{PM}_{10}$ and $\mathrm{PM}_{2.5}$ quartz fiber filters (both front and back-up) of the SFU samples and the fine and coarse filter samples (both front and back) of two HiVol samplers (HVDS1 $1_{\text {UGent }}$ and HVDS2 $\left.{ }_{\text {UGent }}\right)$ for $\mathrm{OC}, \mathrm{EC}$ and $\mathrm{TC}(\mathrm{TC}=\mathrm{OC}+\mathrm{EC})$ with a thermal-optical transmission (TOT) technique (Birch and Cary, 1996; Schmid et al., 2001), using a thermal-optical carbon analyzer from Sunset Laboratory Inc. (Tigard, OR, USA). The analysis was done in a two-stage procedure; one or two $1.5-\mathrm{cm}^{2}$ rectangular punches of each quartz filter were heated stepwise (up to $900^{\circ} \mathrm{C}$ ) in a non-oxidizing helium (He) atmosphere, and then (again up to $900^{\circ} \mathrm{C}$ ) in an oxidizing atmosphere of $2 \%$ oxygen and $98 \%$ He. The carbon that evolves at each temperature is oxidized to carbon dioxide $\left(\mathrm{CO}_{2}\right)$, and then reduced to methane $\left(\mathrm{CH}_{4}\right)$ for quantification with a flame ionization detector (FID). The transmittance of light from a He-Ne laser through the filter punches is continuously monitored and used for setting the OC/EC "split" point, thereby correcting for pyrolysis/charring during the first stage of the analysis.

Max Planck Institute for Chemistry (MPIC) measured total carbon (TC) and the elemental carbon after water extraction $\left(\mathrm{EC}_{w}\right)$ on HiVol samples (HVDS $\mathrm{MPIC}$ ) by evolved gas analysis (EGA) (Mayol-Bracero et al., 2002; Hoffer et al., 2005). The combustion was performed in an oxygen atmosphere, the temperature was increased linearly from $50^{\circ} \mathrm{C}$ to $780^{\circ} \mathrm{C}$ at a rate of $20^{\circ} \mathrm{C} / \mathrm{min}$, and the conversion was completed over a $\mathrm{MnO}_{2}$ catalyst at $800^{\circ} \mathrm{C}$. The EC concentration was determined integrating the last peaks of the thermograms obtained after water extraction (Mayol-Bracero et al., 2002).

\subsection{TOC analysis}

UGent analyzed the fine $(<2.5 \mu \mathrm{m})$ filter samples (both front and back filters) from HVDS1 $1_{\text {UGent }}$ for total organic carbon (TOC). Filter punches of 1 or $1.5 \mathrm{~cm}^{2}$ were placed in a 15 $\mathrm{mL}$ tube, 5 or $10 \mathrm{~mL}$ Millipore Simplicity water was added, and the tube was hand-shaken during $5 \mathrm{~min}$, after which it was allowed to stand for $30 \mathrm{~min}$. The sample extract was then filtered through a PVDF syringe filter (pore size $0.2 \mu \mathrm{m}$ ) and analyzed for TOC, thereby correcting for the inorganic carbon, with a Shimadzu TOC-V CPH analyzer. The TOC data were used as water-soluble OC.

ISAC subjected a sub-set of coarse HiVol (HVDS2 ${ }_{\text {UGent }}$ ) filter samples, having collected supermicron particles $(>2.5 \mu \mathrm{m})$, to TOC analysis. Upon extraction of $\frac{1}{4}$ of filter with $30 \mathrm{ml}$ of deionized water, samples were filtered to remove the filter debris and analyzed by a Shimadzu TOC5000A analyzer. Blank levels were $1 \mathrm{ppm} \mathrm{C}$ and $0.25 \mathrm{ppm} \mathrm{C}$, when filtering with hydrophilic cellulose filters and PTFE hydrophobic filters, respectively. Only coarse $(>2.5 \mu \mathrm{m})$ filters from the transition and the wet periods could be analyzed, because of the relatively low interference from fine particles (Graham et al., 2002).

Pre-cleaned Tedlar substrates mounted on a 5-stage Berner impactor were extracted by ISAC in $6 \mathrm{ml}$ of deionized water in an ultrasonic bath, and analyzed by means of a Shimadzu TOC5000A analyzer. Blank levels were around 0.2 ppm C and a total of 37, 12, 5 size-segregated samples were analyzed for the dry, transition and wet periods, respectively.

\subsection{GC-MS ${ }_{\text {MPIC }}$}

MPIC analyzed the fine fraction of the aerosols collected by the HVDS MPIC sampler for individual polar compounds by gas chromatography-mass spectrometry (GCMS) (Hewlett Packard 6890 GC-MSD) after derivatization. The method was adapted from Graham et al. (2002). The samples $\left(3.5-5.3 \mathrm{~cm}^{2}\right.$ of the filter) were extracted in 4 $6 \mathrm{ml}$ of acetonitrile for $1 \mathrm{~h}$, agitated once every $15 \mathrm{~min}$. The extract was then filtered through a $0.45 \mu \mathrm{m}$ pore size PTFE syringe filter (Pall). An internal standard (3,3dimethylglutaric acid) was added to $3 \mathrm{ml}$ of filtered sample solution, which was then brought to dryness under a gentle stream of $\mathrm{N}_{2}$. After this process, $50 \mu \mathrm{l}$ pyridine and $50 \mu \mathrm{l}$ bis(trimethylsilyl)trifluoroacetamide (BSTFA), containing $1 \%$ trimethylchlorosilane (TMCS) as a catalyst (Supelco), were added to the samples, which were then put into an oven at $70^{\circ} \mathrm{C}$ for $30 \mathrm{~min}$. The sample was injected onto a HP5-MS column $(30 \mathrm{~m} \times 250 \mu \mathrm{m} ; 0.25 \mu \mathrm{m}$ film thickness $)$ equipped with a Supelco guard column (deactivated methylsiloxane, $1 \mathrm{~m} \times 0.32 \mathrm{~mm}$ ) in the splitless mode at $280^{\circ} \mathrm{C}$. The temperature of the oven was held at $65^{\circ} \mathrm{C}$ for $10 \mathrm{~min}$ and ramped at $10^{\circ} \mathrm{C} / \mathrm{min}$ to $310^{\circ} \mathrm{C}$ and held for $10 \mathrm{~min}$. The mass spectrometer was operated both in the selected ion monitoring and full scan mode, and it was calibrated with aliquots of a stock solution of authentic standards. Repeated analysis of the samples showed that the precision of the method was about $20 \%$.

\subsection{GC-MS}

The University of Antwerp (UA) determined a series of polar organic compounds in aerosol samples, i.e., in the front fine filters of all HVDS1 $1_{\text {UGent }}$ samples and the aluminum 
foils from selected MOUDI UGent $_{\text {collections, by using }}$ gas chromatography-mass spectrometry (GC-MS) following derivatization into trimethylsilyl derivatives. Two methods were employed: the first method was targeted to the quantitation of sugar-like compounds (i.e., anhydrosugars, the 2-methyltetrols, $\mathrm{C}_{5}$ alkene triol derivatives of isoprene, the monosaccharides, and the sugar-alcohols), while the second method was targeted to the quantitation of acidic compounds (i.e., hydroxy monocarboxylic acids, dicarboxylic acids, hydroxy dicarboxylic acids and aromatic acids).

Method 1: The first method was adapted from one previously described for the determination of levoglucosan in urban aerosols (Pashynska et al., 2002). Before extraction, the recovery standard, methyl $\beta$-L-xylanopyranoside was added. The aluminum foils were also spiked with a second internal recovery standard, deuterated $\left(\mathrm{d}_{3}\right)$ - malic acid (2,2,3- $\mathrm{d}_{3}$-malic acid; Cambridge Isotope Laboratories, Andover, MA, USA), for measurement of malic acid. Sample workup consisted of extraction with 3 times $20 \mathrm{ml}$ dichloromethane:methanol $(4: 1, \mathrm{v} / \mathrm{v})$ and trimethylsilylation of the extract residue with $50 \mu \mathrm{l}$ of a $3: 5(\mathrm{v} / \mathrm{v})$ mixture of pyridine and $\mathrm{N}$-methyl-N-trimethylsilyltrifluoroacetamide containing $1 \%$ trimethylchlorosilane (MSTFA+1\% TMCS). GC-MS analysis was performed with a TRACE GC2000 gas chromatograph and a Polaris Q ion trap mass spectrometer equipped with an external electron ionization source (ThermoFinnigan, San Jose, CA, USA) using an electron energy of $70 \mathrm{eV}$. The gas chromatograph was equipped with a deactivated silica precolumn $(2 \mathrm{~m} \times 0.25 \mathrm{~mm}$ i.d. $)$ and a $\mathrm{CP}$ Sil 8CB low-bleed capillary column (95\% dimethyl-, 5\% phenylpolysiloxane, $0.25 \mu \mathrm{m}$ film thickness, $30 \mathrm{~m} \times 0.25 \mathrm{~mm}$ i.d.; Chrompack, Middelburg, The Netherlands). The following temperature program was applied: the initial temperature was $50^{\circ} \mathrm{C}$ and kept for $5 \mathrm{~min}$, the temperature was then increased to $200^{\circ} \mathrm{C}$ at the rate of $3^{\circ} \mathrm{C} / \mathrm{min}$ and kept at that temperature for a further $2 \mathrm{~min}$ and then raised to $310^{\circ} \mathrm{C}$ at the rate of $30^{\circ} \mathrm{C} / \mathrm{min}$. The total analysis time was $62 \mathrm{~min}$. For derivatization of standard solutions of all saccharidic compounds, the same procedure was applied. The quantification was based on an internal standard calibration procedure employing methyl $\beta$-L-xylanopyranoside (and $\mathrm{d}_{3}$-malic acid in case of the $\mathrm{Al}$ foils) as internal recovery standard and pure reference compounds, if available.

Method 2: The second method employs the same analytical principles as method 1 and is also based on the use of internal recovery standards. All glassware used for sample workup was deactivated with 5\% dimethyldichlorosilane in toluene in order to minimize adsorption and loss of polar acidic compounds. Before extraction, three recovery standards $(3.75 \mu \mathrm{g}$ of each) were added to the filter sample: (a) deuterated glutaric acid (2,2,4,4- $\mathrm{d}_{4}$-pentanedioic acid; Cambridge Isotope Laboratories), (b) deuterated malic acid (2,2,3- $\mathrm{d}_{3}$-malic acid; Cambridge Isotope Laboratories) and (c) tropic acid (3-hydroxy-2-phenylpropionic acid; Fluka, Buchs, Switzerland). Deuterated glutaric acid served as in- ternal recovery standard for the dicarboxylic acids, i.e., glutaric acid, succinic acid and fumaric acid. Deuterated malic acid served as internal recovery standard for the hydroxy mono- and dicarboxylic acids, i.e., malic acid, glyceric acid, $\alpha$ - and $\beta$-hydroxy glutaric acid, threonic acid, an isomer of threonic acid, and tartaric acid. Tropic acid served as internal recovery standard for the aromatic acids, i.e., 2-, 3- and 4hydroxybenzoic acid, vanillic acid and isovanillic acid. Extraction was performed in $25 \mathrm{~mL}$ Pyrex flasks with methanol (3 times with $20 \mathrm{~mL}$ ) under ultrasonic agitation for $15 \mathrm{~min}$. The subsequent steps were the same as for method 1. For assessing the amounts of the analytes, the response factor of pure reference compounds was used.

For both methods, duplicate analyses show that the precision of the determinations was about $10 \%$. All reported concentrations are corrected for procedural blanks.

\subsection{IC}

The Weizmann Institute (WI) performed analyses of filter and impactor samples by ion chromatography (IC). For HVDS2 UGent samples, a $\frac{1}{4}$ fraction of the fine filter was extracted twice into $5 \mathrm{ml}$ of water, by short vortex agitation followed by $15 \mathrm{~min}$ of gentle shaking. The combined extract was centrifuged for $5 \mathrm{~min}$ and filtered through a GHP Acrodisk ${ }^{\circledR}$ syringe filter $(25 \mathrm{~mm}, 0.45 \mu \mathrm{m}$ pore size; Gelman, Pall Corporation, NY, USA), which had been previously washed with $10 \mathrm{ml}$ water. Selected MOUDI IFUSP samples and half of each SFU sample were extracted in the same manner into $4 \mathrm{ml}$ of water. These were filtered using a GHP Acrodisk $^{\circledR}$ syringe filter $(13 \mathrm{~mm}, 0.45 \mu \mathrm{m}$ pore size $)$. It has been validated that further extraction was not needed.

IC analysis was carried out using a Varian ProStar HPLC system equipped with a Dionex ED50 electrochemical detector. Anions were determined using a Dionex AS11 analytical column and ASRS-Ultra suppressor in autosuppression mode. For simultaneous separation of inorganic and short-chain $\left(\mathrm{C}_{1}-\mathrm{C}_{9}\right)$ organic anions, gradient elution by $0.4-$ $25 \mathrm{mM} \mathrm{NaOH}(2 \mathrm{~mL} / \mathrm{min})$ was employed (duration of the analysis: $20 \mathrm{~min}$ ). Cations were determined using a Dionex CS12 column and CSRS-Ultra suppressor in autosuppression mode with $20 \mathrm{mM}$ methanesulfonic acid (MSA) as an eluent $(1 \mathrm{ml} \mathrm{min}-1)$. A thorough validation of extraction and analytical method can be found in Falkovich et al. (2004).

\subsection{IEC}

Sample extracts of the HVDS2 UGent samples obtained as described for IC analysis were further analyzed by ion exclusion chromatography (IEC) by WI. The extracts were purified using Accell ${ }^{\mathrm{TM}}$ QMA solid-phase extraction cartridges (Waters, MA, USA) in order to eliminate HULIS, which interfered with detection. The samples were separated using ion exclusion liquid chromatography using a Dionex ICEAS1 column and a Varian ProStar 230I HPLC pump, and 
polyhydroxy compounds were detected by photodiode array (Varian ProStar 330) at $194 \mathrm{~nm}$ (for a detailed description of the method, see Schkolnik et al., 2005). The method uncertainty is $15 \%$ for concentrations $>0.2 \mu \mathrm{g} / \mathrm{m}^{3}$, and $23 \%$ for concentrations $<0.2 \mu \mathrm{g} / \mathrm{m}^{3}$.

\subsection{IC-UV}

ISAC employed ion-exchange chromatography with UV detection (IC-UV) to fractionate WSOC according to their ionic nature at $\mathrm{pH} 8$. The whole set of 5-stage Berner impactor samples collected during the SMOCC field campaign was analyzed by the IC-UV technique, implemented on a Hitachi L-7100 HPLC system equipped with a Gilson autosampler, a Toso-Haas DEAE-TSK gel column $(7.5 \mathrm{~mm}$ i.d. $\times 7.5 \mathrm{~cm} 1$.), and an UV detector $(260 \mathrm{~nm})$. The aliquots of samples for HPLC analysis were dried under vacuum and re-dissolved with $300 \mu \mathrm{l}$ of mobile phase A, necessary to fill the $100 \mu \mathrm{l}$ loop of the HPLC system. The injection of samples dissolved in the first mobile phase instead of water allowed the suppression of the injection peak in the chromatogram, in order to perform a more accurate integration of the peak arising from non-retained analytes.

The mobile phase was an aqueous solution of $20 \%$ acetonitrile and $\mathrm{NaClO}_{4}$ at the following concentrations: A) 0 $\mathrm{M}$; B) $0.02 \mathrm{M}$; C) $0.4 \mathrm{M}$. The $\mathrm{pH}$ of the mobile phases B and $\mathrm{C}$ was held constant at 8.0 with a $0.01 \mathrm{M}$ TRIS: $\mathrm{HCl}$ buffer. A first isocratic elution was followed by a gradient (from 12 to $15 \mathrm{~min}$ ) changing the solvent composition from $\mathrm{A}$ to $\mathrm{B}$; after $6 \mathrm{~min}$ of isocratic conditions, a second gradient from 21 to 26 min allowed the system to reach the $100 \% \mathrm{C}$ composition. A last five minute gradient changed the composition of the mobile phase to $100 \%$ A. Flow rate was $0.7 \mathrm{ml} \mathrm{min}^{-1}$. The compounds eluted $\mathrm{A}$ ) with the first eluent (from 3 to $17 \mathrm{~min}$ ), B) after the increase of the $\mathrm{NaClO}_{4}$ concentration to $0.02 \mathrm{M}$ (from 17 to $26 \mathrm{~min}$ ), or $\mathrm{C}$ ) after the second increase of the ionic strength (from 26 to $32 \mathrm{~min}$ ) were classified as neutral compounds (NC), mono-/diacids (MDA) and polyacids (PA), respectively. Compared to the original analytical procedure proposed by Decesari et al. (2000), the elution method used in the present study improves the separation between NC and the acidic fractions, allowing to overcome the elution problems with the phenolic compounds (Chang et al., 2005). The attribution of the separated fractions to chemical classes has been verified by injection of standard compounds (their retention time in minutes is indicated in parentheses in the following listing) selected to represent all the classes of polar organic compounds known to occur in biomass burning aerosol (Graham et al., 2002). NC: D-galactal (4.5), D-glucal (4.5), furfuryl alcohol (5.0), benzyl alcohol (5.6), vanillin (9.8), phenol (10.2), m-cresol (11.9); MDA: glyoxylic acid (19.2), sodium formate (19.7), sodium oxalate (23.4), malic acid (23.9), potassium hydrogen-phthalate (25.1); PA: 1,3,5benzene-tricarboxylic acid (28.3), citric acid (28.5), Suwannee River fulvic acid (ca. 29). Clearly, the retention times of all the standards match with those expected according to the classification into the three main chromatographic fractions (Decesari et al., 2005).

Calibration factors to convert the peak areas of NC, MDA and PA into their specific carbon concentrations were provided by chromatographic fractions isolated on preparative glass columns of DEAE-cellulose gel. Buffer solutions of ammonium bicarbonate were used for selective elution of NC, MDA and PA. In order to improve the resolution while keeping low the volume of mobile phase necessary to elute the strongly retained compounds, two columns, A and B (lengths: $1 \mathrm{~cm}+4 \mathrm{~cm}$ ), were initially used in series to separate $\mathrm{NC}$ from the acidic compounds retained on the column. MDA were subsequently eluted with the $0.02 \mathrm{M}$ buffer, while in a second step PA were eluted with $1 \mathrm{M}$ buffer directly from column A by-passing B. This procedure allows the elution of each fraction with an amount of ammonium bicarbonate low enough to be easily removed by rotary evaporation. The isolated fractions were then analyzed for TOC and by HPLC, providing an external calibration for the HPLC technique. The precision of the procedure for providing calibration factors is $8 \%$ for NC and PA and $20 \%$ for MDA, while the variability between samples belonging to homogeneous sets (e.g., the samples of the dry, transition or wet periods) introduces an uncertainty of $10-20 \%$ up to $30 \%$ in the case of NC in the coarse aerosol samples.

\section{$2.9 \quad{ }^{1}$ HNMR spectroscopy}

The water extracts of Tedlar foils from two Berner impactor samples collected in the dry period (on 23 September during daytime, and during the night of 25-26 September) were dried and redissolved in $0.7 \mathrm{~mL}$ of $\mathrm{D}_{2} \mathrm{O}$ containing an internal standard $\left(0.24 \mathrm{mM}\right.$ sodium 3-trimethylsilyl-2,2,3,3- $d_{4}$ propanoate (TSP)) for ${ }^{1} \mathrm{HNMR}$ analysis at $400 \mathrm{MHz}$. From the sample collected on 23 September, only the three impactor stages corresponding to the size fractions $0.05-0.14$, $0.14-0.42$ and $0.42-1.2 \mu \mathrm{m}$ provided sufficient amounts of sample for the ${ }^{1} \mathrm{HNMR}$ analysis. Water extracts of HVDS2 UGent samples representative of the three periods of the campaign were also dried and redissolved with $0.24 \mathrm{mM}$ TSP in $\mathrm{D}_{2} \mathrm{O}$ for ${ }^{1} \mathrm{HNMR}$ analysis at $400 \mathrm{MHz}$ or $600 \mathrm{MHz}$. Finally, the same procedure was applied to the chromatographic fractions isolated on preparative glass columns of DEAE-cellulose gel (see previous section) from the water extract of the $\mathrm{PM}_{2.5}$ HVDS2 $2_{\mathrm{UGent}}$ sample (front filter) collected during the night of 25-26 September, under very polluted conditions in the dry period. Details of the ${ }^{1}$ HNMR experimental conditions are reported by Tagliavini et al. (2005). The concentration of carboxylic groups $(\mathrm{COOH})$ was directly determined in selected samples, through a derivatization procedure into methyl esters, as also discussed by Tagliavini et al. (2005). Samples undergoing derivatization${ }^{1}$ HNMR analysis included HVDS2 2 UGent fine and coarse filters representative of the three campaign periods, and the 
(a) TC, EC and WSOC in fine PM

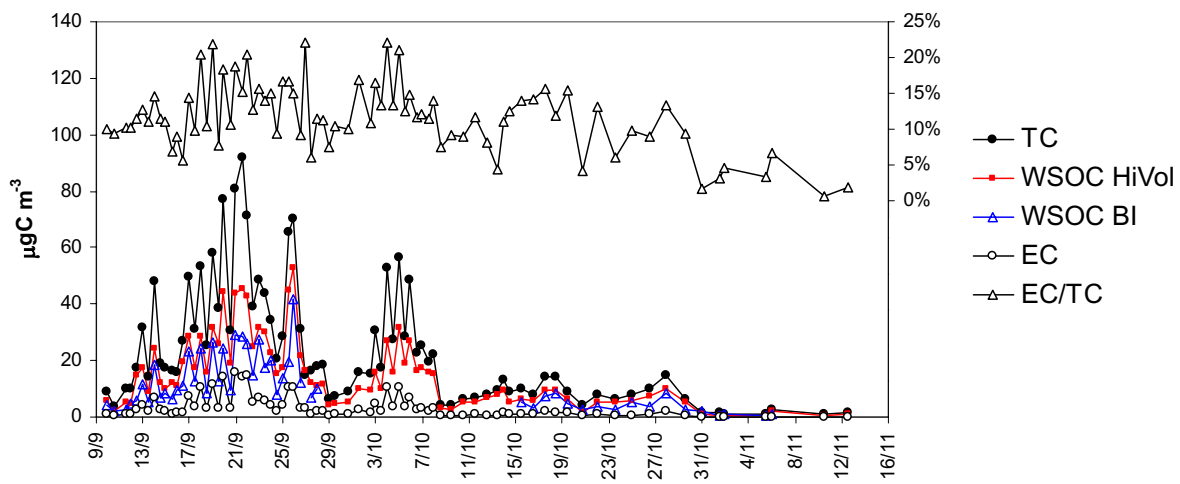

(b) TC and WSOC in coarse PM

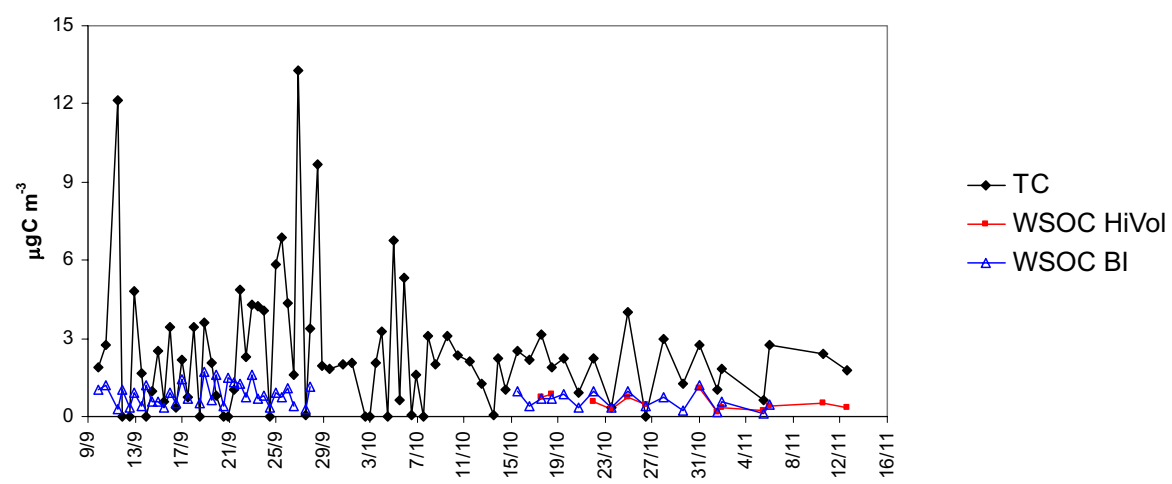

Fig. 1. Trends of TC, EC and WSOC concentrations $\left(\mu \mathrm{g} \mathrm{C} \mathrm{m}^{-3}\right)$ in the fine (a) and coarse (b) fractions of the aerosol during the LBASMOCC experiment. The profile of the EC/TC $(\%)$ ratio is also reported for the fine fraction. TC concentrations were determined on $\mathrm{PM}_{10}$ and $\mathrm{PM}_{2.5}$ SFU samples equipped with quartz fiber filters, and deployed by UGent. The concentration of EC was obtained by EGA analysis of $\mathrm{PM}_{2.5}$ HVDS MPIC filter samples. The WSOC concentrations were determined in the fine and coarse fractions of the aerosol on HVDS1 $1_{\text {UGent }}$ and HVDS2 ${ }_{\text {UGent }}$ filter samples, respectively. All concentrations determined on HVDS samples have been corrected for sampling biases relative to the UGent SFU samplers. WSOC concentrations determined on the Berner impactor (BI) samples are also reported for the fine fraction $(0.05-1.2 \mu \mathrm{m})$ and for the coarse one $(1.2-10 \mu \mathrm{m})$.

three chromatographic fractions obtained from the sample HVDS2 $2_{\text {UGent }}$ collected on 25-26 September. The overall ${ }^{1}$ HNMR experiment was conducted by the University of Bologna (UniBO).

\section{Results}

\subsection{Concentrations and trends of TC, EC and total WSOC}

Figure 1 shows the temporal trends of TC from the TOT analysis of the SFU samples in the fine and coarse size fractions throughout the experiment. EC data provided by EGA anal-

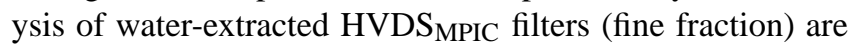
also reported after correction for sampling biases between the HiVol and the SFU systems. Data are already corrected for the back-up filter contribution. EC accounts for 5 to $20 \%$ of TC in the fine fraction of the aerosol (Table 1). These data are in agreement with results reported in the literature on biomass burning in tropical forests (Reid et al., 2005). It should be noted that the EC values provided by EGA analysis of water-extracted filters are about six-fold higher than those measured by TOT analysis (not shown in the figure), while they are in reasonable agreement with those determined by means of a Ruprecht and Patashnik (R\&P) 5400 carbon analyzer (Fuzzi et al., $2006^{1}$ ). The partitioning between OC and EC in TOT analysis depends strongly on the temperature program used (Schmid et al., 2001), especially for biomass smoke aerosols, and suffers from artifacts when filters are heavily loaded (Kubátová et al., 1999). 
Table 1. (a) EC/TC for the fine fraction of the aerosol and (b) WSOC/TC ratios for the fine and coarse fractions in the different periods of the LBA-SMOCC campaign. EC/TC data were obtained by EGA analysis of HVDS MPIC samples, whereas WSOC/TC ratios were obtained on HVDS1 $1_{\text {UGent }}$ and HVDS2 ${ }_{\text {UGent }}$ filter samples. Average values and standard deviations (in parentheses) are reported for all the samples in each period (N/D), and specifically for the samples collected at night (N) and day-time (D).

(a) $\mathrm{EC} / \mathrm{TC}$

\begin{tabular}{lccc}
\hline period & fine & & \\
& $\mathrm{N} / \mathrm{D}$ & $\mathrm{N}$ & $\mathrm{D}$ \\
\hline dry & $0.13(0.04)$ & $0.15(0.04)$ & $0.10(0.03)$ \\
trans. & $0.10(0.03)$ & $0.12(0.02)$ & $0.08(0.03)$ \\
wet & $0.03(0.02)$ & $0.04(0.02)$ & $0.03(0.00)$ \\
all samples & $0.11(0.05)$ & & \\
\hline
\end{tabular}

(b) WSOC/TC

\begin{tabular}{llccccc}
\hline period & fine & & \multicolumn{2}{c}{ coarse } \\
& $\mathrm{N} / \mathrm{D}$ & $\mathrm{N}$ & $\mathrm{D}$ & $\mathrm{N} / \mathrm{D}$ & $\mathrm{N}$ & $\mathrm{D}$ \\
\hline dry & $0.64(0.08)$ & $0.61(0.06)$ & $0.67(0.08)$ & $0.37(0.13)$ & $0.35(0.13)$ & $0.37(0.13)$ \\
trans. & $0.69(0.09)$ & $0.66(0.03)$ & $0.68(0.12)$ & $0.31(0.07)$ & $0.31(0.02)$ & $0.28(0.05)$ \\
wet & $0.53(0.11)$ & $0.54(0.16)$ & $0.46(0.06)$ & $0.28(0.12)$ & $0.33(0.14)$ & $0.21(0.04)$ \\
all samples & $0.64(0.09)$ & & & $0.34(0.12)$ & & \\
\hline
\end{tabular}

The figure also shows the concentrations of total WSOC determined on HVDS1 $1_{\text {UGent }}$ and HVDS2 $2_{\text {UGent }}$ filters after correction for the sampling biases with relative to the SFU filters, plus the total WSOC determined on the Berner impactor samples obtained by lumping the impactor stages corresponding to an aerosol diameter $<1.2 \mu \mathrm{m}$ (fine fraction), and those sampling between 1.2 and $10 \mu \mathrm{m}$ (coarse fraction). Generally, the Berner impactor was less efficient than the filter-based techniques in sampling WSOC in the fine fraction, providing concentrations $30 \%$ lower on average during the first part of the campaign, when the aerosol concentrations were highest and the discrepancy between the samplers largest. The air concentrations of WSOC are always well correlated with those of TC and PM (the latter are not shown in the figure), with temporal trends that reflect the main factors controlling the aerosol loads in the boundary layer as discussed in a parallel paper (Fuzzi et al., 2006 ${ }^{1}$ ). Clearly, the high aerosol concentrations of submicrometer carbonaceous particles observed in September and the beginning of October (i.e., the dry period) must be attributed to the intense biomass burning activities in Rondônia and Mato Grosso, and other upwind Brazilian states at that time. Under high pressure meteorological conditions, the height of the tropical continental boundary layer undergoes a diurnal cycle, which causes fluctuations in the aerosol loads with clear maxima during the night. After the intense precipitation event on 8 October, the concentrations of biomass burning particles started to increase again but without reaching the peaks observed in the dry period. This period was denoted as the "transition period". Finally, "wet" conditions with frequent rain episodes became established after 1 November, leading to a substantial decrease in the concentrations of the fine particles, down to approx. $4 \%$ relative to the average concentrations observed in the dry period.

Conversely, the TC in the coarse fraction underwent a much less pronounced decrease from the dry to the wet period (Fig. 1b), suggesting that its concentrations were only partly affected by the biomass burning emissions and were controlled mainly by other sources that also hold for periods of intense precipitation. In contrast to the strong dominance of submicrometer WSOC mass during dry conditions, the concentrations of the WSOC in the fine and coarse fractions were of the same order of magnitude $\left(0.90\right.$ and $0.45 \mu \mathrm{g} \mathrm{C} / \mathrm{m}^{3}$ on average, respectively) during the wet period. The trends in WSOC concentrations in the fine and coarse fractions closely follow those of TC. However, the average WSOC/TC ratios are different, indicating that coarse carbonaceous particles have a lower WSOC content (Table 1b). The analysis of the chemical tracers indicates that biological particles contributed to the coarse fraction of the aerosol (see the following discussion). Large biological particles emitted by vegetation typically contain substances that are essentially water-unextractable, such as cell membranes and walls, epi-cuticular materials, as well as water-soluble compounds trapped inside intact cells (Graham et al., 2003). Therefore, the occurrence of large biological particles is a plausible explanation for the less soluble character of coarse carbonaceous particles collected at FNS. Conversely, WSOC dominate the composition of TC in fine particles from biomass burning sources. During the dry period, a limited but significant increase in the WSOC percentage was observed during day-time compared to the night. This difference can be 


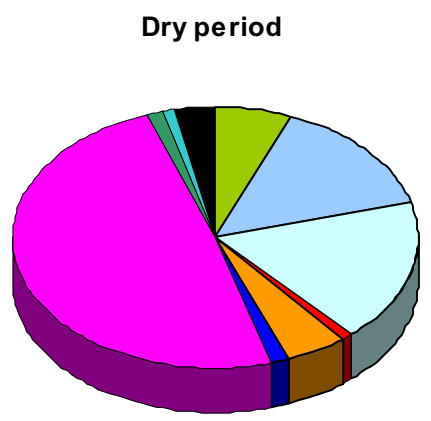

Transition period

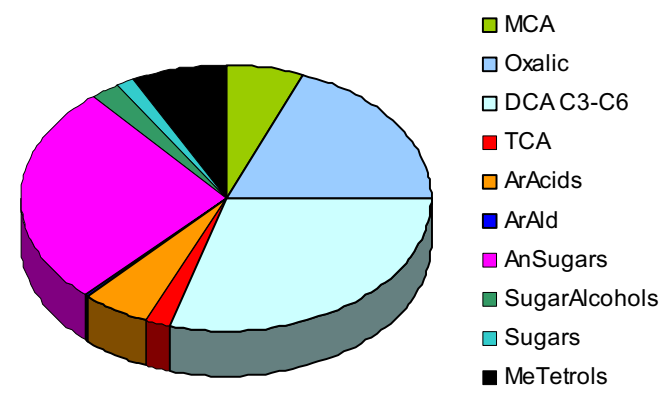

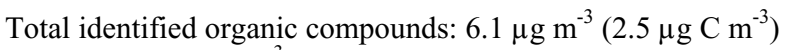
WSOC: $19.5 \mu \mathrm{g} \mathrm{C} \mathrm{m}^{-3}$ OC: $26.9 \mu \mathrm{g} \mathrm{C} \mathrm{m}^{-3}$

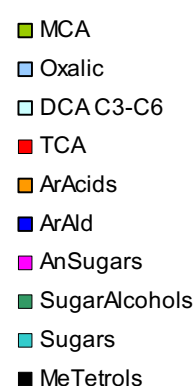

- MeTetrols
Total identified organic compounds: $1.6 \mu \mathrm{g} \mathrm{m}^{-3}\left(0.6 \mu \mathrm{g} \mathrm{C} \mathrm{m}^{-3}\right)$ WSOC: $6.4 \mu \mathrm{g} \mathrm{C} \mathrm{m}^{-3}$ OC: $8.0 \mu \mathrm{g} \mathrm{C} \mathrm{m}^{-3}$

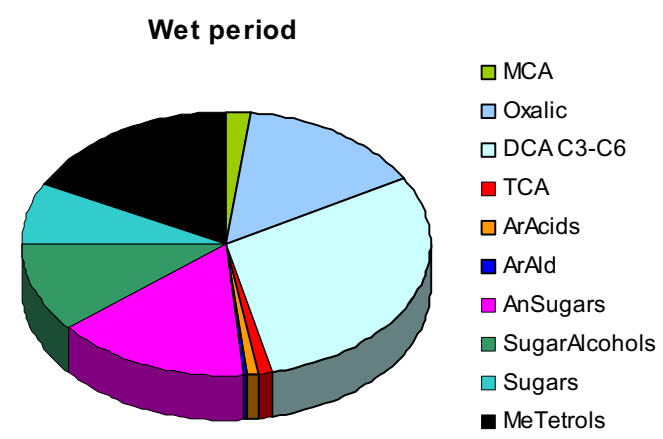

Total identified organic compounds: $0.25 \mu \mathrm{g} \mathrm{m}^{-3}\left(0.10 \mu \mathrm{g} \mathrm{C} \mathrm{m}^{-3}\right)$ WSOC: $0.85 \mu \mathrm{g} \mathrm{C} \mathrm{m}^{-3}$ OC: $1.42 \mu \mathrm{g} \mathrm{C} \mathrm{m}^{-3}$

Fig. 2. Mean composition of the WSOC fraction speciated at the molecular level by GC-MS, IC and IEC methods in fine filter samples collected in the different periods of the campaign. Average concentrations of monocarboxylic acids (MCA) and oxalic acid were obtained by the results of IEC and IC analysis of the HVDS2 ${ }_{\text {UGent }}$ and IFUSP SFUs samples (Table 2). Mean concentrations for $\mathrm{C}_{3}-\mathrm{C}_{6}$ dicarboxylic acids (DCA C3-C6), aromatic aldehydes (ArAld), sugar-alcohols, sugars and 2-methyltetrols (MeTetrols) were provided by GC-MS analysis of the HVDS1 $1_{\text {UGent }}$ and HVDS MPIC filters. The concentrations of the other classes of compounds (tricarboxylic acids (TCA), aromatic acids (ArAcids) and anhydrosugars (AnSugars)) are averages of the mean values for the different sets of HVDS and SFU samples analyzed by GC-MS, IC and IEC. For each period of the campaign, the reconstructed total concentration of the organic compounds identified by GC-MS, IC and IEC is reported together with the average OC and WSOC concentrations determined on HVDS samples by TOT (for TC), EGA (for $\mathrm{EC}_{w}$ ) and TOC (for WSOC) analysis. All concentrations determined for the HVDS samples are corrected for the sampling biases between each HiVol system and the SFU samplers with quartz fiber filters operated by UGent, as for Table 2.

attributed either to the different combustion stages occurring during the day compared to night (i.e., more frequent flaming than smoldering fires), or to the photochemical production of secondary organic compounds during day (Hoffer et al., 2005). Therefore, different sources of biomass burning aerosols and secondary processes are likely to affect the soluble/insoluble character of the fine particles in the dry period.

\subsection{OC speciation in the fine and coarse aerosol}

Using the diverse analytical techniques for individual compound analysis, as described in the experimental section, we identified and quantified a series of polar organic compounds with 1 to 12 carbon atoms per molecule, comprising different chemical classes: monocarboxylic, dicarboxylic and tricarboxylic acids, aromatic acids and aldehydes, sugars, sugaralcohols and anhydrosugars. A summary of the results of WSOC speciation from the analysis of filter samples is given in Table 2, while a pie chart (Fig. 2) shows the relative concentrations of the main categories of compounds identified in fine PM for the various periods of the campaign. The four sets of data available for the composition of submicron particles exhibit discrepancies in the concentrations of specific classes of compounds. However, since the statistics for each series are not based on the same number of samples, a general conclusion on the recovery of the different sampling systems and analytical methods cannot be provided here. 
Table 2a. Concentrations of the identified organic compounds (in $\mathrm{ng} \mathrm{m}^{-3}$ ) in fine and coarse filter samples, following GC-MS, IC and IEC analysis. Average values and range of variation are reported for the dry (Table 2a), transition (Table 2b) and wet (Table 2c) periods. Total identified organic compounds, WSOC, OC and TC data are reported as $\mu \mathrm{g} \mathrm{m}^{-3}$. MCA: aliphatic mono-carboxylic acids; DCA: aliphatic

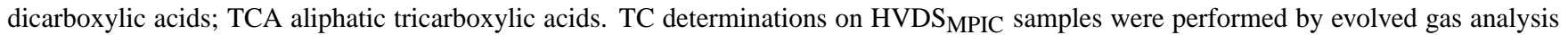
(Hoffer et al., 2005), while TC/OC analyses for the two HVDS systems operated by UGent were performed by TOT. Finally, total WSOC concentrations were determined by TOC analysis. Concentrations determined for the HVDS samples are corrected for the sampling biases between each HiVol system and the SFU samplers with quartz fiber filters operated by UGent. Sampling biases were estimated by comparing the TC values obtained on the different sets of samples, and therefore could not be assessed for the SFU IFUSP samples, which were equipped with Nuclepore ${ }^{\circledR}$ substrates unsuitable for TC analysis.

\begin{tabular}{|c|c|c|c|c|c|}
\hline Dry period & $\begin{array}{l}\text { Fine } \\
\quad \text { HVDS1 }_{\text {UGent }} \\
\text { GC-MS }_{\mathrm{UA}}(\mathrm{N}=51)\end{array}$ & $\begin{array}{c}\text { HVDS }_{\text {MPIC }} \\
\text { GC-MS }_{\text {MPIC }}(\mathrm{N}=17)\end{array}$ & $\begin{array}{l}\text { HVDS2 } 2 \text { UGent } \\
\text { IC+IEC }(\mathrm{N}=16)\end{array}$ & $\begin{array}{c}\text { SFU IFUSP IC }_{(\mathrm{N}=19)} \\
\end{array}$ & $\begin{array}{c}\text { Coarse } \\
\text { SFU IFUSP IC } \\
(\mathrm{N}=19)\end{array}$ \\
\hline MCA & & & $594(119-1472)$ & $139(22.9-413)$ & $80.3(6.1-264)$ \\
\hline glyceric acid & $71.4(22.1-169)$ & $58.0(22.9-98.0)$ & & & \\
\hline formic acid & & & $137(56.2-294)$ & $88.5(12.1-370)$ & $17.2(2.5-43.8)$ \\
\hline MSA & & & $12.7(4.9-18.4)$ & $25.2(0.0-213)$ & $32.0(0.0-465)$ \\
\hline glyoxylic acid & & & $79.8(19.4-181)$ & $40.5(0.0-115)$ & $0.80(0.0-15.1)$ \\
\hline Oxalic acid & & & $1233(409-2463)$ & $516(92.2-932)$ & $162(19.2-305)$ \\
\hline DCA C $\mathrm{C}_{3}-\mathrm{C}_{9}$ & & & $874(169-1497)$ & $566(139-1026)$ & $19.7(0.0-106)$ \\
\hline malonic acid & & $153(23.3-350)$ & $127(55.5-287)$ & $53.7(0.0-210)$ & \\
\hline methylmalonic acid & & $5.8(3.0-9.3)$ & & & \\
\hline succinic acid & $659(125-2213)$ & $149(61.8-261)$ & & & \\
\hline methylsuccinic acid & & $18.3(7.2-34.8)$ & & & \\
\hline maleic acid & & $21.5(7.0-75.0)$ & $25.7(10.3-52.6)$ & $9.8(0.0-29.3)$ & \\
\hline fumaric acid & $71.1(22.5-276)$ & $10.7(4.9-17.5)$ & $8.9(2.2-21.7)$ & $5.2(0.0-20.3)$ & \\
\hline malic acid & $397(152-858)$ & $169(96-228)$ & & & \\
\hline glutaric acid & $57.5(9.0-187)$ & $24.1(11.0-40.3)$ & & & \\
\hline$\alpha$-hydroxyglutaric acid & $186(61.7-449)$ & & & & \\
\hline$\beta$-hydroxyglutaric acid & $46.8(16.2-111)$ & & & & \\
\hline 2-ketoglutaric acid & & $31.7(0.0-50.9)$ & & & \\
\hline threonic acid (+isomer) & $83.5(24.3-206)$ & & & & \\
\hline tartaric acid & $50.9(18.6-104)$ & & & & \\
\hline adipic acid & & $7.9(3.8-16.8)$ & & & \\
\hline pimelic acid & & $4.9(2.8-9.4)$ & & & \\
\hline azelaic acid & & & $10.1(0.0-30.9)$ & & \\
\hline \multicolumn{6}{|l|}{ TCA } \\
\hline citric acid & & & $54.1(20.3-95.2)$ & $48.4(0.0-114)$ & \\
\hline tricarballylic acid & & $23.0(15.0-36.5)$ & $57.0(6.4-14.4)$ & $42.8(0.0-89.3)$ & \\
\hline \multicolumn{6}{|l|}{ Aromatic acids } \\
\hline phtalic acid & & $30.5(16.2-57.2)$ & $22.0(0.0-55.3)$ & & \\
\hline isophtalic acid & & $3.7(1.3-7.4)$ & & & \\
\hline 2-hydroxybenzoic acid & $5.6(0.5-20.3)$ & & & & \\
\hline 3-hydroxybenzoic acid & $3.0(0.2-14.5)$ & $10.6(2.8-22.6)$ & $83.2(26.4-183)$ & $78.2(0.0-183)$ & \\
\hline 4-hydroxybenzoic acid & $33.3(2.3-117)$ & $48.9(15.0-124)$ & & & \\
\hline 3,4-dihydroxybenzoic acid & & $51.2(23.2-109)$ & & & \\
\hline vanillic acids & $81.1(4.9-255)$ & $54.1(12.4-136)$ & $93.7(26.0-174)$ & $16.8(0.0-67.3)$ & \\
\hline syringic acid & & $74.6(6.8-194)$ & $109(31.2-342)$ & $86.4(0.0-225)$ & \\
\hline \multicolumn{6}{|l|}{ Aromatic aldehydes } \\
\hline 4-hydroxybenzaldehyde & & $4.6(0.6-16.0)$ & & & \\
\hline vanillin & & $10.2(1.3-27.6)$ & & & \\
\hline syringaldehyde & & $66.8(6.2-216)$ & & & \\
\hline \multicolumn{6}{|l|}{ Other aromatics } \\
\hline 4-methylbenzcatechin & & $5.2(1.1-16.6)$ & & & \\
\hline \multicolumn{6}{|l|}{ Anhydrosugars } \\
\hline galactosan & $58.7(7.7-261)$ & $80.3(16.4-193)$ & & & \\
\hline mannosan & $152(23.7-543)$ & $151(34.0-345)$ & & & \\
\hline levoglucosan & $2222(284-7485)$ & $3698(763-7903)$ & 1307 (92-6514) & & \\
\hline anhydroglucofuranose & $97.8(16.3-435)$ & & & & \\
\hline \multicolumn{6}{|l|}{ Sugar-alcohols } \\
\hline glycerol & & $14.3(6.6-35.8)$ & & & \\
\hline erythritol & & $51.7(18.5-155)$ & & & \\
\hline threitol & & $11.9(1.4-24.0)$ & & & \\
\hline arabitol & $16.7(0.0-41.4)$ & $30.9(9.0-57.4)$ & & & \\
\hline mannitol & $21.9(3.8-52.3)$ & $25.0(7.5-44.6)$ & & & \\
\hline sorbitol & & $1.0(0.4-1.9)$ & & & \\
\hline inositol & & $1.0(0.0-2.1)$ & & & \\
\hline \multicolumn{6}{|l|}{ Sugars } \\
\hline fructose & & $20.7(11.2-44.3)$ & & & \\
\hline sucrose & & $4.9(1.3-11.0)$ & & & \\
\hline \multicolumn{6}{|l|}{ Methyl-tetrols } \\
\hline 2-methyl-threitol & $53.7(8.7-98.3)$ & & & & \\
\hline 2-methyl-erythritol & $148(26.7-318)$ & & & & \\
\hline Total identified & $4.5(1.1-13.3)$ & $6.2(1.7-12.7)$ & $3.4(1.0-6.4)$ & $1.68(0.36-3.69)$ & $0.26(0.08-0.55)$ \\
\hline WSOC & $20.5(4.4-52.6)$ & $33.3(19.0-55.2)$ & $23.3(9.4-49.7)$ & & \\
\hline OC & $31.6(6.1-76.3)$ & & $35.2(14.4-69.8)$ & & \\
\hline TC & $32.7(6.4-78.2)$ & $51.7(24.9-90.9)$ & $36.4(14.9-72.0)$ & & \\
\hline
\end{tabular}


Table 2b.

\begin{tabular}{|c|c|c|c|c|c|}
\hline Transition & $\begin{array}{l}\text { Fine } \\
\quad \text { HVDS1 } 1_{U G e n t} \\
\text { GC-MS }_{U A}(N=20)\end{array}$ & $\begin{array}{c}\text { HVDS }_{\text {MPIC }} \\
\text { GC-MS }_{\text {MPIC }}(\mathrm{N}=13)\end{array}$ & $\begin{array}{l}\text { HVDS2 } \\
\text { IC+IEC }(\mathrm{N}=5)\end{array}$ & $\begin{array}{l}\text { SFU IFUSP IC } \\
\quad(\mathrm{N}=8)\end{array}$ & 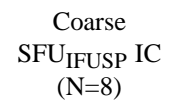 \\
\hline MCA & & & $164(112-215)$ & $27.8(8.4-46.0)$ & $10.6(0.3-25.7)$ \\
\hline glyceric acid & $32.4(16.3-47.6)$ & $13.7(6.9-19.3)$ & & & \\
\hline formic acid & & & $32.5(19.0-45.8)$ & $17.0(3.7-31.5)$ & $2.0(0.1-4.3)$ \\
\hline MSA & & & $6.9(3.3-11.7)$ & $3.4(0.0-11.1)$ & \\
\hline glyoxylic acid & & & $25.1(19.6-31.7)$ & $10.9(0.0-24.4)$ & \\
\hline Oxalic acid & & & $434(347-490)$ & $177(65.9-265)$ & $55.5(8.4-123)$ \\
\hline DCA C $\mathrm{C}_{3}-\mathrm{C}_{9}$ & & & 345 (257-463) & $295(63.6-514)$ & \\
\hline malonic acid & & $31.5(3.0-58.1)$ & $48.2(30.1-59.6)$ & $14.4(0.0-43.8)$ & \\
\hline methylmalonic acid & & $1.1(0.4-1.9)$ & & & \\
\hline succinic acid & $276(99.9-609)$ & $22.3(8.4-47.3)$ & & & \\
\hline methylsuccinic acid & & $3.1(1.2-5.3)$ & & & \\
\hline maleic acid & & $4.7(1.0-19.2)$ & $18.3(9.3-28.5)$ & $7.3(0.0-15.8)$ & \\
\hline fumaric acid & $36.5(13.3-63.1)$ & $2.7(1.2-5.0)$ & $5.3(3.7-8.5)$ & $3.5(0.0-7.7)$ & \\
\hline malic acid & $268(163-413)$ & $69.7(39.3-104)$ & & & \\
\hline glutaric acid & $21.7(8.3-43.4)$ & $3.5(1.3-7.3)$ & & & \\
\hline$\alpha$-hydroxyglutaric acid & $77.7(37.5-133)$ & & & & \\
\hline$\beta$-hydroxyglutaric acid & $26.7(13.1-45.7)$ & & & & \\
\hline 2-ketoglutaric acid & & $8.4(2.9-23.4)$ & & & \\
\hline threonic acid (+ isomer) & $41.9(23.1-60.6)$ & & & & \\
\hline tartaric acid & $47.9(25.5-78.3)$ & & & & \\
\hline adipic acid & & $1.3(0.5-2.9)$ & & & \\
\hline pimelic acid & & $0.7(0.4-1.3)$ & & & \\
\hline azelaic acid & & & & & \\
\hline TCA & & & & & \\
\hline citric acid & & & $21.1(14.8-33.8)$ & $22.9(7.3-44.9)$ & \\
\hline tricarballylic acid & & $11.3(5.9-18.7)$ & $16.7(14.4-20.9)$ & $16.0(4.9-31.7)$ & \\
\hline Aromatic acids & & & & & \\
\hline phtalic acid & & & $4.0(0.0-6.7)$ & & \\
\hline isophtalic acid & & $0.9(0.4-1.5)$ & & & \\
\hline 2-hydroxybenzoic acid & $0.7(0.1-2.3)$ & & & & \\
\hline 3-hydroxybenzoic acid & $0.4(0.0-1.5)$ & $0.8(0.2-2.3)$ & $55.4(40.8-86.4)$ & $38.2(6.1-79.5)$ & \\
\hline 4-hydroxybenzoic acid & $4.9(0.7-14.4)$ & $4.6(0.8-13.5)$ & & & \\
\hline 3,4-dihydroxybenzoic acid & & $8.0(1.5-17.8)$ & & & \\
\hline vanillic acids & $12.8(1.9-39.1)$ & $3.2(0.5-9.5)$ & $9.9(0.0-26.1)$ & $12.6(0.0-24.0)$ & \\
\hline syringic acid & & $6.3(0.4-16.6)$ & $30.8(25.3-42.9)$ & $39.0(0.0-77.1)$ & \\
\hline Aromatic aldehydes & & & & & \\
\hline 4-hydroxybenzaldehyde & & $0.4(0.1-1.6)$ & & & \\
\hline vanillin & & $1.0(0.2-2.9)$ & & & \\
\hline syringaldehyde & & $3.7(0.7-12.0)$ & & & \\
\hline Other aromatics & & & & & \\
\hline 4-methylbenzcatechin & & $0.4(0.1-0.8)$ & & & \\
\hline Anhydrosugars & & & & & \\
\hline galactosan & $11.4(2.7-32.2)$ & $9.0(1.4-22.7)$ & & & \\
\hline mannosan & $30.6(7.3-69.6)$ & $16.8(3.3-39.1)$ & & & \\
\hline levoglucosan & $399(106-858)$ & 425 (89.9-893) & $256(32.6-609)$ & & \\
\hline anhydroglucofuranose & $22.5(6.8-41.9)$ & & & & \\
\hline Sugar-alcohols & & & & & \\
\hline glycerol & & $3.3(1.3-5.6)$ & & & \\
\hline erythritol & & $7.5(3.1-15.3)$ & & & \\
\hline threitol & & $1.4(0.3-2.7)$ & & & \\
\hline arabitol & $9.9(4.5-22.1)$ & $12.0(5.2-24.4)$ & & & \\
\hline mannitol & $20.2(9.5-46.8)$ & $18.1(3.8-46.3)$ & & & \\
\hline sorbitol & & $0.8(0.2-2.1)$ & & & \\
\hline inositol & & $0.4(0.0-0.7)$ & & & \\
\hline Sugars & & & & & \\
\hline fructose & & $5.8(1.9-9.1)$ & & & \\
\hline sucrose & & $1.6(0.8-4.6)$ & & & \\
\hline Methyl-tetrols & & & & & \\
\hline 2-methyl-threitol & $26.1(7.6-89.1)$ & & & & \\
\hline 2-methyl-erythritol & $93.9(22.4-312)$ & & & & \\
\hline Total identified & $1.4(0.7-2.3)$ & $0.9(0.3-1.6)$ & $1.1(0.9-1.3)$ & $0.63(0.1-1.25)$ & $0.1(0.0-0.2)$ \\
\hline WSOC & $6.2(1.5-10.1)$ & $7.2(5.1-10.2)$ & $7.3(5.5-9.2)$ & & \\
\hline OC & $8.6(2.9-15.2)$ & & $10.5(7.5-13.6)$ & & \\
\hline TC & $9.0(3.1-15.8)$ & $9.4(5.4-14.9)$ & $10.9(8.0-14.0)$ & & \\
\hline
\end{tabular}


Table 2c.

\begin{tabular}{|c|c|c|c|c|c|}
\hline Wet period & $\begin{array}{l}\text { Fine } \\
\text { HVDS1 }_{\text {UGent }} \\
\text { GC-MS }_{\mathrm{UA}}(\mathrm{N}=7)\end{array}$ & $\begin{array}{c}\text { HVDS }_{\text {MPIC }} \\
\text { GC-MS }_{\text {MPIC }}(\mathrm{N}=7)\end{array}$ & $\begin{array}{l}\text { HVDS2 } \\
\text { IC+IEC }(\mathrm{N}=0)\end{array}$ & $\begin{array}{c}\text { SFU IFUSP IC }_{(\mathrm{N}=7)} \\
\text { ( }\end{array}$ & $\begin{array}{c}\text { Coarse } \\
\text { SFU IFUSP IC } \\
(\mathrm{N}=7)\end{array}$ \\
\hline MCA & & & & $5.2(2.5-6.7)$ & $11.2(4.6-20.8)$ \\
\hline $\begin{array}{l}\text { glyceric acid } \\
\text { formic acid }\end{array}$ & $4.0(1.3-6.3)$ & $1.5(0.5-2.5)$ & & $9.4(6.6-18.0)$ & $0.4(0.0-1.3)$ \\
\hline \multicolumn{6}{|l|}{$\begin{array}{l}\text { MSA } \\
\text { glyoxylic acid }\end{array}$} \\
\hline Oxalic acid & & & & $36.7(23-51.6)$ & $16.0(7.7-28.3)$ \\
\hline DCA C $_{3}-\mathrm{C}_{9}$ & & & & $33.9(14.7-61.0)$ & $4.0(0.0-11.4)$ \\
\hline malonic acid & & $5.0(1.8-7.1)$ & & $5.2(0.0-8.1)$ & \\
\hline methylmalonic acid & & $0.2(0.1-0.4)$ & & & \\
\hline succinic acid & $28.6(8.4-48.8)$ & $2.5(1.2-3.8)$ & & & \\
\hline methylsuccinic acid & & $0.3(0.1-0.5)$ & & & \\
\hline maleic acid & & $0.9(0.3-2.7)$ & & & \\
\hline fumaric acid & $7.1(3.9-12.3)$ & $0.5(0.3-0.9)$ & & & \\
\hline malic acid & $76.7(39.5-113)$ & $15.5(8.3-24.6)$ & & & \\
\hline glutaric acid & $4.4(0.0-11.7)$ & $0.4(0.2-0.8)$ & & & \\
\hline$\alpha$-hydroxyglutaric acid & $8.7(3.8-18.0)$ & & & & \\
\hline$\beta$-hydroxyglutaric acid & $4.6(2.0-7.1)$ & & & & \\
\hline 2-ketoglutaric acid & & $0.8(0.0-1.3)$ & & & \\
\hline threonic acid (+ isomer) & $6.7(3.6-10.7)$ & & & & \\
\hline tartaric acid & $14.6(5.9-24.2)$ & & & & \\
\hline adipic acid & & $0.4(0.2-0.5)$ & & & \\
\hline pimelic acid & & $0.2(0.1-0.4)$ & & & \\
\hline \multicolumn{6}{|l|}{ azelaic acid } \\
\hline TCA & & & & & \\
\hline \multicolumn{6}{|l|}{ citric acid } \\
\hline tricarballylic acid & & $2.7(1.3-5.3)$ & & & \\
\hline \multicolumn{6}{|l|}{ Aromatic acids } \\
\hline phtalic acid & & $1.5(0.4-2.3)$ & & & \\
\hline isophtalic acid & & $0.1(0.0-0.4)$ & & & \\
\hline 2-hydroxybenzoic acid & $0.1(0.0-0.1)$ & & & & \\
\hline 3-hydroxybenzoic acid & $0.0(0.0-0.1)$ & $0.1(0.0-0.3)$ & & & \\
\hline 4-hydroxybenzoic acid & $0.3(0.1-0.6)$ & $0.0(0.0-0.1)$ & & & \\
\hline 3,4-dihydroxybenzoic acid & & $0.4(0.1-1.0)$ & & & \\
\hline vanillic acid & $1.1(0.2-3.5)$ & $0.3(0.1-0.8)$ & & & \\
\hline isovanillic acid & & & & & \\
\hline \multicolumn{6}{|l|}{ Aromatic aldehydes } \\
\hline 4-hydroxybenzaldehyde & & $0.0(0.0-0.1)$ & & & \\
\hline vanillin & & $0.2(0.0-0.8)$ & & & \\
\hline syringaldehyde & & $0.1(0.0-0.4)$ & & & \\
\hline \multicolumn{6}{|l|}{ Other aromatics } \\
\hline 4-methylbenzcatechin & & $0.1(0.0-0.2)$ & & & \\
\hline \multicolumn{6}{|l|}{ Anhydrosugars } \\
\hline galactosan & $1.1(0.0-2.4)$ & $0.6(0.2-1.1)$ & & & \\
\hline mannosan & $4.2(1.9-7.9)$ & $1.3(0.4-2.5)$ & & & \\
\hline levoglucosan & $59.7(15.7-160)$ & $35.8(9.6-74.3)$ & $44.5(0.0-89.1)$ & & \\
\hline anhydroglucofuranose & $2.4(1.1-4.9)$ & & & & \\
\hline \multicolumn{6}{|l|}{ Sugar-alcohols } \\
\hline glycerol & & $1.3(0.8-2.4)$ & & & \\
\hline erythritol & & $2.2(0.5-3.3)$ & & & \\
\hline threitol & & $0.2(0.1-0.4)$ & & & \\
\hline arabitol & $8.9(5.4-11.9)$ & $10.4(5.8-13.6)$ & & & \\
\hline mannitol & $18.0(11.2-21.2)$ & $23.5(12.1-31.5)$ & & & \\
\hline sorbitol & & $1.1(0.7-1.4)$ & & & \\
\hline inositol & & $0.1(0.1-0.2)$ & & & \\
\hline \multicolumn{6}{|l|}{ Sugars } \\
\hline fructose & & $4.0(2.5-5.9)$ & & & \\
\hline sucrose & & $0.9(0.4-2.4)$ & & & \\
\hline \multicolumn{6}{|l|}{ Methyl-tetrols } \\
\hline 2-methyl-threitol & $9.3(3.1-20.3)$ & & & & \\
\hline 2-methyl-erythritol & $34.7(13.2-65.6)$ & & & & \\
\hline Total identified & $0.3(0.2-0.5)$ & $0.1(0.1-0.2)$ & & $0.09(0.05-0.13)$ & $0.03(0.01-0.04)$ \\
\hline WSOC & $0.9(0.7-2.0)$ & $1.4(0.9-1.8)$ & & & \\
\hline OC & $1.4(0.9-2.5)$ & & & & \\
\hline TC & $1.5(0.9-2.7)$ & $1.7(0.9-2.2)$ & & & \\
\hline
\end{tabular}


In general, the IC analysis provided higher concentrations of monocarboxylic, tricarboxylic and aromatic acids compared to the GC-MS methods. The GC-MS analysis following the UA methods (denoted by $\mathrm{GC}-\mathrm{MS}_{\mathrm{UA}}$ ) provided higher values for the dicarboxylic acids and lower for the sugar-derivatives compared to the analysis performed with the MPIC method (denoted by GC-MS ery of low-molecular weight compounds, such as $\mathrm{C}_{3}-\mathrm{C}_{6}$ dicarboxylic acids (DCA) by GC-MS can be affected by the different extraction techniques employed. The levoglucosan concentrations obtained with the GC-MS $\mathrm{UA}_{\mathrm{UA}}$ method are in agreement with the results of the IEC-UV method which does not require a derivatization step (Schkolnik et al., 2005). Therefore, the deviation between the two methods shown in the table is merely due to the different sets of samples analyzed. Further, it is noted that the levoglucosan concentrations obtained with the GC-MS $\mathrm{UA}_{\mathrm{UA}}$ method are in good agreement with those for the LBA-EUSTACH-2 campaign, which had been conducted at the same pasture site (Graham et al., 2002). A possible reason for the large discrepancies obtained for measurement of polar carboxylic acids between the two GC-MS methods is the different polarity of the extraction solvents used: the GC-MS $\mathrm{UA}_{\mathrm{UA}}$ method uses methanol as an extraction solvent, and internal recovery standards that allow to correct for losses during sample workup, while the GC$\mathrm{MS}_{\text {MPIC }}$ method uses acetonitrile (less polar than methanol) as extraction solvent and assumes a 100\% recovery.

The pie charts in Fig. 2 were obtained by averaging the mean concentrations for the different sets of HVDS and SFU samples analyzed by GC-MS, IC or IEC. However, given the systematic differences between the analytical methods with respect of the recovery for specific categories of compounds, the average concentrations for MCA and oxalic acid were based only on the HVDS2 2 Gent and SFU samples analyzed by IC, while we retrieved average concentrations for DCA $\mathrm{C}_{3}-\mathrm{C}_{9}$, aromatic aldehydes, sugar-alcohols, sugars and 2methyl-tetrols only from the sets of HVDS samples analyzed by GC-MS.

The data in Tables $2 \mathrm{a}$ and $\mathrm{b}$ can be directly compared with the GC-MS results from the 1999 LBA-EUSTACH-2 campaign (Graham et al., 2002). The coarse filters collected during the SMOCC campaign were subjected to a less comprehensive set of analyses than used in LBA-EUSTACH, and sugar-derivatives were not measured. In the case of the submicron particles, on the other hand, the combination of speciation methods in the present study, comprising both GC and LC techniques provided a more detailed picture of the organic composition. In particular, in addition to the di- and tricarboxylic acids, benzoic and vanillic acids, and sugarderivatives already identified and measured by Graham et al. (2002), the analysis of the LBA-SMOCC samples indicated higher concentrations of monocarboxylic acids and significant concentrations of dicarboxylic acids, hydroxy monoand dicarboxylic acids, and 2-methyltetrols. The identified chemical compounds are classified as follows:
- $C_{1}-C_{3}$ monocarboxylic acids: acetic, formic, methanesulfonic, lactic, glyoxylic and glyceric acids. They represent 4 to $7 \%$ of total aliphatic acids. Monocarboxylic acids have multiple sources, including both biomass burning and biogenic emissions (Souza et al., 1999);

- $C_{2}-C_{9}$ aliphatic dicarboxylic acids: oxalic acid was found to be by far the most abundant carboxylic acid identified, followed by malonic, succinic and malic acid, and with a clear increase in the relative contribution of the latter species towards the end of the campaign. Oxalic acid can originate from multiple sources, both primary and secondary. It was recently found as the most abundant carboxylic acid in biomass burning smoke in South Africa (Gao et al., 2003). Conversely, malic acid shows a more pronounced biogenic origin and was found to accompany photooxidation products of isoprene (i.e., 2-methyltetrols) in the Amazon basin (Claeys et al., 2004a);

- Aliphatic tricarboxylic acids: they include citric and tricarballylic acids, and account for only 1 to $2 \%$ of the mass of total speciated organic compounds. They have been previously reported (Graham et al., 2002);

- One-ring aromatic acids and aldehydes: the aromatic compounds include methoxylated species (vanillin, syringaldehyde and the corresponding acids) and hydroxy-benzoic acids. The methoxylated compounds are more abundant compared to the hydroxy-benzoic acids in the dry season, whereas the contrary holds starting from the transition period. The concentration of the aromatic compounds clearly decreases relatively to aliphatic acids from 1:5 in the dry period to 1:25 in the wet period. One-ring aromatic acids and aldehydes are primary compounds known to be produced by the combustion of lignins (Simoneit, 2002) and are, therefore, enriched in fresh biomass burning smoke;

- Sugars and sugar-derivatives: they comprise both pyrogenic (anhydrosugars; Graham et al., 2002; Zdráhal et al., 2002) and biogenic (sugars and sugar-alcohols; Simoneit et al., 2004) compounds. Levoglucosan is the most abundant single compound identified in submicron aerosols during the whole campaign, including the wet period. However, the concentration of levoglucosan and the other anhydrosugars clearly decreases relative to the biogenic compounds (sugars and sugar-alcohols), from 10:1 in the dry to $9: 10$ in the wet period;

- 2-Methyltetrols: they were identified as major biogenic compounds in the Amazon basin, and were attributed to photo-oxidation of isoprene (Claeys et al., 2004a). Principal component analysis confirmed that the concentrations of 2-methyltetrols in the SMOCC filter samples do not correlate with those of pyrogenic compounds, 
such as levoglucosan and potassium sulfate (Maenhaut et al., 2005, in preparation). Figure 2 also shows that 2-methyltetrols account for a very small fraction of the identified WSOC mass during the dry period, whereas they add up to $10 \%$ of the speciated mass in the wet period, following the decrease of the concentrations of the pyrogenic organic compounds.

The tracer analysis clearly indicates a more pronounced signature of the biogenic sources in the wet period compared to the previous periods of the campaign. After averaging the concentrations from the various filter substrates and analytical techniques (Fig. 2), the classes of identified organic compounds of clearly pyrogenic origin (i.e., aromatic acids and aldehydes and anhydrosugars) account for 55, 33 and 16\% of the total speciated compounds in the dry, transition and wet periods, respectively, while the corresponding fractions for the biogenic species (i.e., sugars, sugar-alcohols and 2methyl-tetrols) are 6,11 and 36\%. The relatively high concentrations of levoglucosan and other pyrogenic compounds in the samples from November suggest that the biomass burning activity was not totally suppressed at the beginning of the wet season. In that period, persistent fire activity could be detected in Rondônia and Mato Grosso in areas temporarily free from precipitations (http://www.master.iag.usp. br/queimadas/). Finally, the increase in the concentrations of aliphatic carboxylic acids compared to anhydrosugars and aromatic compounds towards the end of the campaign may reflect more pronounced secondary sources due to oxidation of either pyrogenic and biogenic VOCs. The enrichment of the aliphatic carboxylic acids compared to anhydrosugars is known to occur during the transport of biomass burning products (Gao et al., 2003). After the onset of wet conditions, a longer transport from distant sparse fires, as well as more pronounced in-cloud processing, would favor the production of secondary organic compounds, rendering a more chemically aged character to the aerosol OC. The same conclusion can be derived from the change in the size-segregated inorganic chemical composition from the dry to the wet period (Fuzzi et al., 2006 ${ }^{1}$ ).

Table 2 also reports the sum of concentrations of identified organic compounds and the aerosol TC, OC and WSOC for the same periods. The recovery of the speciation methods is higher in the case of the GC-MS $\mathrm{UA}$ analysis on the HVDS1 $1_{\text {UGent }}$ samples, where the identified compounds account for 6 to $8 \%$ of TC, and 9 to $11 \%$ of WSOC on a carbon basis. When comparing the reconstructed total concentration of the compounds identified by GC-MS $\mathrm{UA}_{\mathrm{A}}, \mathrm{GC}-\mathrm{MS}_{\mathrm{MPIC}}$, IC and IEC techniques with the average OC and WSOC concentrations for the three main periods of the campaign (Fig. 2), we obtain a recovery of $7-9 \%$ for OC and of $10-13 \%$ for WSOC (Fig. 2). These values must be treated with caution, since the sets of samples analyzed by GC-MS ${ }_{\text {MPIC }}$, IC and IEC are a subset of the filters used for TC and WSOC determination. In any case, it is clear that a large part of the or- ganic matter was not amenable to GC-MS, IC and IEC analysis because it could not be eluted or derivatized into stable products, and eventually eluded identification at the molecular level.

\subsection{OC speciation in the size-segregated samples}

Selected samples of the 12-stage MOUDI ${ }_{U G \text { Gent }}$ were subjected to OC speciation by GC-MS $\mathrm{UA}$, while samples of the 10-stage MOUDI IFUSP were analyzed by IC and IEC-UV techniques, providing the size-distributions of the most important identified organic compounds in the three periods of the campaign (Falkovich et al., 2004; Claeys et al., 2006, $2006^{2}$; Schkolnik et al., 2005). The resulting size-segregated organic composition in terms of identified chemical classes is plotted for samples representative from the dry, transition and wet periods in Figs. $3 \mathrm{a}$ and $\mathrm{b}$. The concentrations of the speciated OC classes are expressed as percentages of the aerosol mass in each size bin. Figure 3a reports the sizesegregated composition of the carboxylic acids determined by IC analysis. Monocarboxylic acids, oxalic acid and $\mathrm{C}_{3}$ $\mathrm{C}_{9}$ dicarboxylic acids are the main contributors to the acidic organic fraction in all the size intervals, although aromatic compounds are also important in the dry and transition periods, but only for particles with a diameter lower than $1 \mu \mathrm{m}$. Conversely, aromatic acids were not detected in the sample from the wet period in all size intervals. In all periods, the carboxylic acids are less abundant in the finest size range, as well as in the coarse fraction. Their contribution to aerosol mass is also higher in the dry compared to the other two periods. The contribution of the 2-methyltetrols determined by GC-MS $\mathrm{UA}_{\mathrm{UA}}$ to PM (Fig. 3b) also shows a decrease toward the wet period, but only in the submicron fraction, whereas the opposite holds for the coarse fraction. Anhydrosugars are the most abundant compounds in all seasons, with levoglucosan as the main species in the submicron and supermicron fractions, respectively. Sugar-alcohols (arabitol and mannitol) contribute up to almost two thirds of the speciated polyhydroxylated compounds in the size intervals $1.8-10 \mu \mathrm{m}$ in the dry period, but this fraction increases to $60-90 \%$ in the transition phase and to $80-100 \%$ in the wet period. Finally, the contribution of the 2-methyltetrols to OC increases significantly in the wet period, but only in the submicron size intervals.

The data reported in Figs. 3a and b show that the contribution of the identified classes of organic compounds to aerosol PM changes with the aerosol diameter, and is generally highest in the $0.4-4 \mu \mathrm{m}$ range. Since TC was not determined

\footnotetext{
${ }^{2}$ Claeys, M., Kourtchev, I., Pashynska, V., Vas, G., Vermeylen, R., Cafmeyer, J., Chi, X., Artaxo, P., and Maenhaut, W.: Polar organic marker compounds in boundary layer aerosols during the LBA-SMOCC 2002 biomass burning experiment in Rondônia, Brazil: time trends, diurnal variations and size distributions, in preparation, 2006.
} 


\section{2-23 Sept (Dry period)}

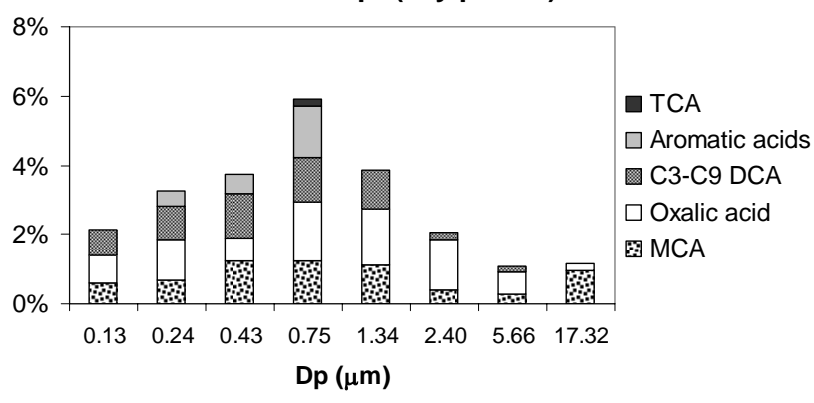

16-18 Oct (Transition)

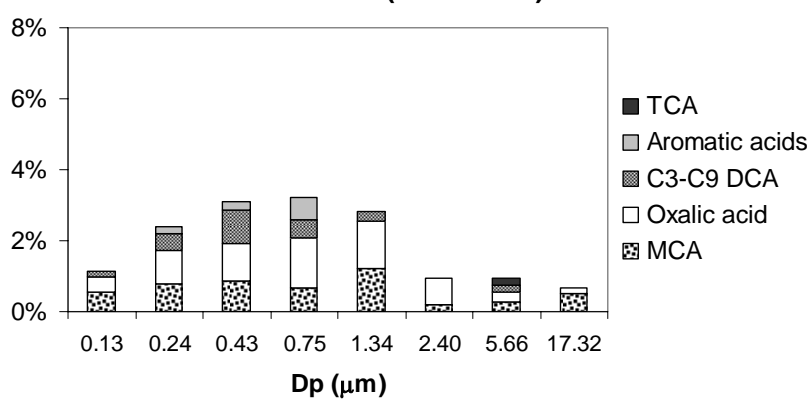

06-10 Nov (Wet period)

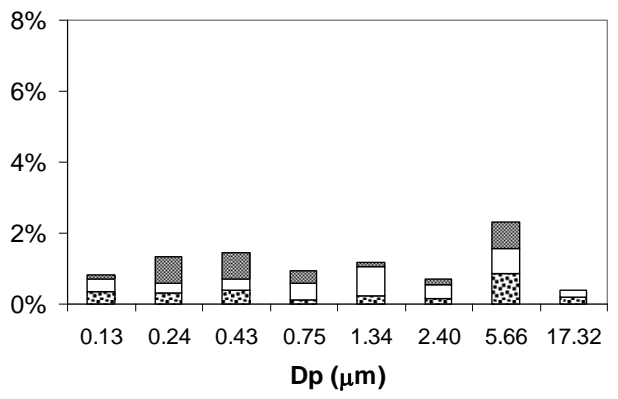

(a)
17-18 Sept (Dry period)

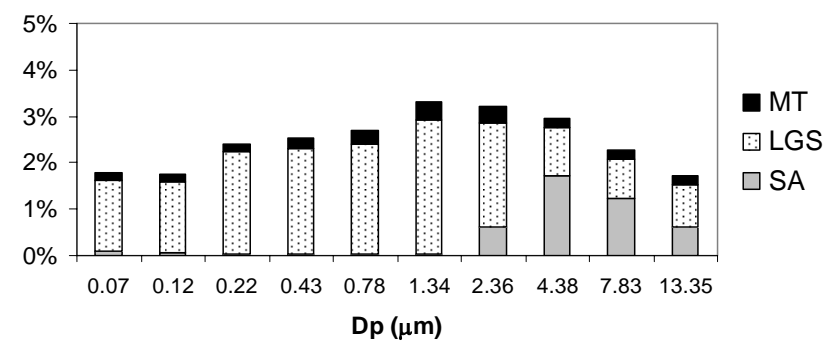

19-19 Oct (Transition)

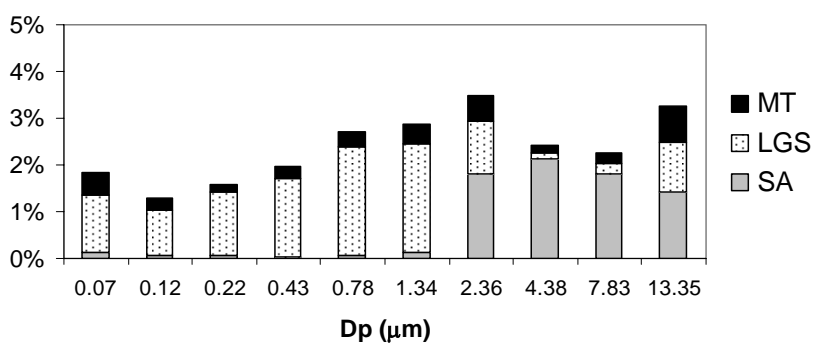

10-12 Nov (Wet period)

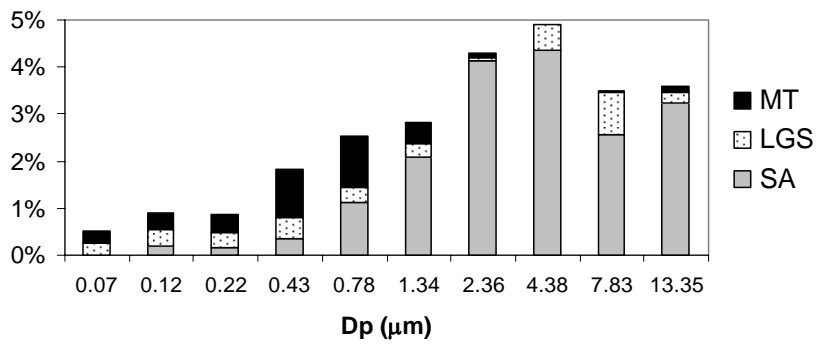

(b)

Fig. 3. Fraction of $\mathrm{PM}$ accounted for by the organic compounds speciated in size-segregated aerosol samples. (a) Carboxylic acids from IC analysis of IFUSP MOUDI samples: aliphatic monocarboxylic acids (MCA), oxalic acid, $\mathrm{C}_{3}-\mathrm{C}_{9}$ dicarboxylic acids (DCA), $\mathrm{C}_{7}-\mathrm{C}_{8}$ aromatic acids and aliphatic tricarboxylic acids (TCA). (b) Polyhydroxylated compounds from GC-MS analysis of UGent MOUDI samples: 2-methyltetrols (MT), levoglucosan (LGS) and sugar-alcohols (SA) (arabitol and mannitol). Both figures report the results for three different samples representative of the three main periods of the campaign. The horizontal axis gives the geometric mean of the lower and upper cut-off diameters of the MOUDI stages.

systematically on MOUDI samples, a size-segregated carbon balance was not attempted in this study.

\subsection{Apportionment of WSOC into main chemical classes}

Compared to the methods for WSOC speciation discussed so far, the IC-UV technique presented in the experimental section is a chromatographic method for the separation of broad chemical classes of WSOC, which is not targeted to speciation at the molecular level. The neutral compounds (NC), mono-/diacids (MDA) and the polyacids (PA) separated by
IC-UV were identified mainly on the basis of their chromatographic behavior (i.e., the retention time). The quantitative analysis is based on the determination of the TOC on isolated fractions used to calibrate the UV detector. Therefore, the concentrations of NC, MDA and PA could be derived only as $\mu \mathrm{g}$ of carbon per cubic meter, as for total WSOC. Other than some improvements in the chromatographic conditions, the method is essentially the same as the one used for the analysis of $\mathrm{PM}_{2.5}$ samples during the LBA-EUSTACH campaign (Mayol-Bracero et al., 2002a). 

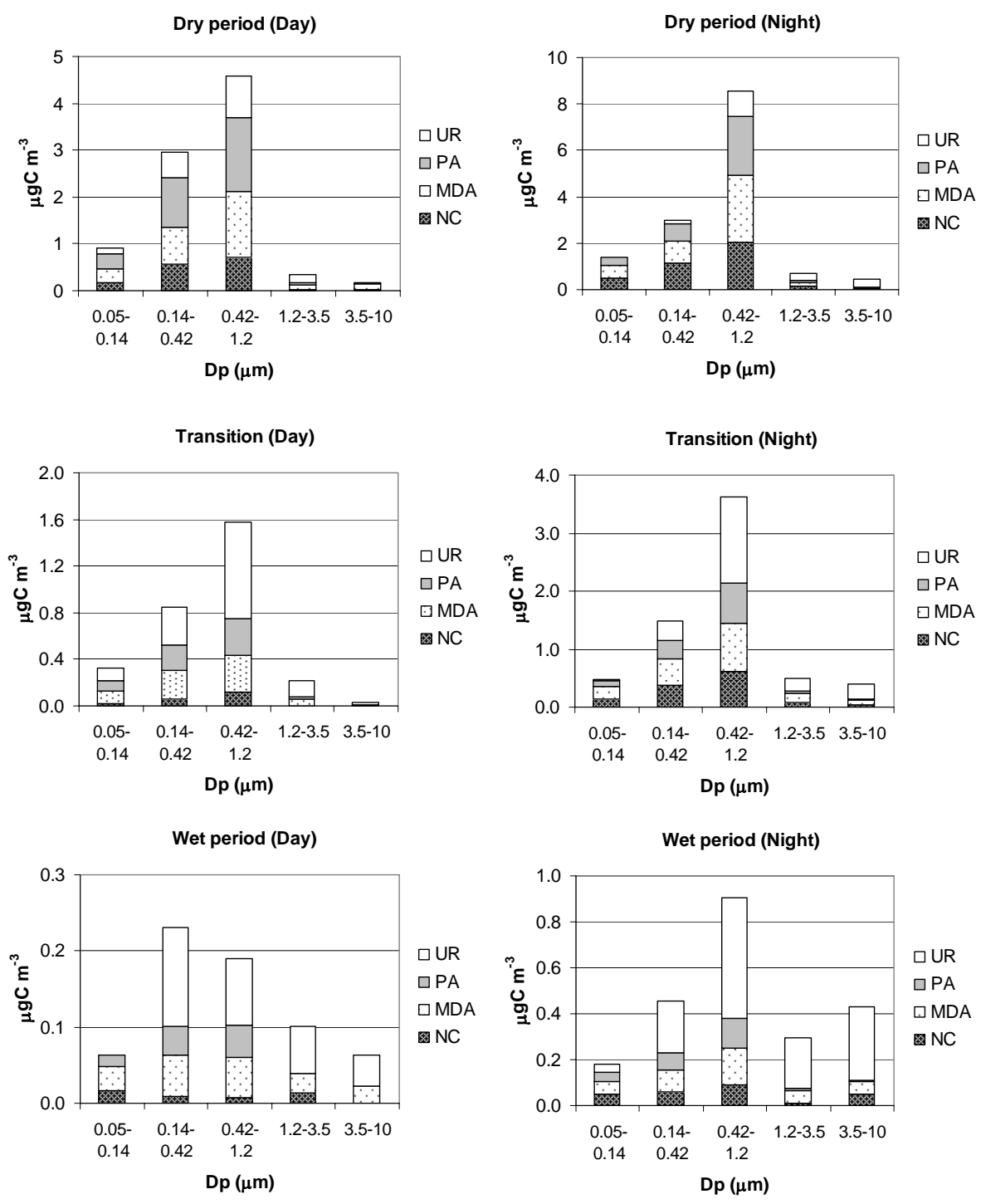

Fig. 4. Average concentrations of the WSOC chemical classes determined by the IC-UV method on the Berner impactor samples. NC: neutral compounds; MDA: mono-/diacids; PA: polyacids; UR: unresolved, i.e., WSOC fraction not accounted for by IC-UV analysis. Mean concentrations are reported for the three main periods of the campaign and separately for the samples collected during night-time and those collected during day-time.

The NC, MDA and PA were detected by UV absorption at $260 \mathrm{~nm}$ in all samples analyzed, provided that the injected WSOC amount exceeded $500 \mathrm{ng}$ C. Using calibration following the procedure described in the experimental section, the HPLC peak areas of the three main regions of the chromatogram provided the concentrations of NC, MDA and PA in the size range $0.05-3.5 \mu \mathrm{m}$ (stages I to IV of the Berner impactor) for 37 samples from the dry period, 12 samples from the transition period and 5 samples from the wet period, whereas the concentrations in larger particles (3.5$10 \mu \mathrm{m})$ were often below the detection limit. Table 3 reports the statistics for the concentrations of NC, MDA and $\mathrm{PA}$ in size-segregated samples from the three periods and also separately for nocturnal and diurnal samples. The mean relative contributions of the three IC-UV classes to the total water-soluble carbon are also included. Average sizesegregated distributions for the three chemical classes and for the WSOC fraction unresolved by the IC-UV method are shown in Fig. 4 for the three main periods of the campaign.

A constant feature for all samples is the substantially lower relative concentration of PA in the coarse size range compared to the submicron size fraction. PA show a particularly low abundance in coarse particles from the wet period. MDA exhibit rather constant contributions to WSOC in the submicron particles, whereas their contribution to WSOC in the coarse particles is quite variable. Finally, the NC fraction of 
Table 3. Concentrations of WSOC, neutral compounds (NC), mono-/diacids (MDA) and polyacids (PA) determined by the IC-UV method for the Berner impactor. Mean values and standard deviations (in parentheses) are reported for the whole set of samples for each period (N/D), and specifically for the samples collected at night (N) and during day-time (D).

\begin{tabular}{|c|c|c|c|c|c|c|c|c|c|}
\hline & & & & Concentratior & $\left(\mu \mathrm{gCm}^{-3}\right)$ & & & $6 \mathrm{WSOC}$ & \\
\hline & & $\mathrm{Dp}(\mu \mathrm{m})$ & WSOC & $\mathrm{NC}$ & MDA & PA & $\mathrm{NC}$ & MDA & PA \\
\hline Dry period & $\mathrm{N} / \mathrm{D}(\mathrm{n}=37)$ & $0.05-0.141 .35(0.93)$ & $0.40(0.38)$ & $0.46(0.31)$ & $0.38(0.24)$ & $28 \%$ & $35 \%$ & $31 \%$ & \\
\hline & & $0.14-0.42$ & $3.59(2.17)$ & $0.99(0.89)$ & $1.08(0.75)$ & $1.08(0.76)$ & $26 \%$ & $30 \%$ & $30 \%$ \\
\hline & & $0.42-1.2$ & $8.96(6.94)$ & $2.18(2.20)$ & $2.97(2.56)$ & $2.72(2.66)$ & $21 \%$ & $32 \%$ & $31 \%$ \\
\hline & & $1.2-3.5$ & $0.64(0.63)$ & $0.12(0.18)$ & $0.18(0.17)$ & $0.10(0.13)$ & $15 \%$ & $28 \%$ & $14 \%$ \\
\hline & & $3.5-10$ & $0.29(0.18)$ & $0.04(0.02)$ & $0.09(0.04)$ & $0.02(0.01)$ & $9 \%$ & $18 \%$ & $5 \%$ \\
\hline & $\mathrm{N}(\mathrm{n}=18)$ & $0.05-0.14$ & $1.75(1.10)$ & $0.65(0.41)$ & $0.60(0.33)$ & $0.43(0.24)$ & $43 \%$ & $37 \%$ & $25 \%$ \\
\hline & & $0.14-0.42$ & $3.73(2.24)$ & $1.32(1.01)$ & $1.18(0.75)$ & $0.97(0.76)$ & $28 \%$ & $31 \%$ & $25 \%$ \\
\hline & & $0.42-1.2$ & $12.76(7.70)$ & $3.43(2.42)$ & $4.17(2.91)$ & $3.65(3.38)$ & $24 \%$ & $34 \%$ & $26 \%$ \\
\hline & & $1.2-3.5$ & $0.91(0.81)$ & $0.20(0.23)$ & $0.24(0.21)$ & $0.15(0.17)$ & $18 \%$ & $25 \%$ & $12 \%$ \\
\hline & & $3.5-10$ & $0.40(0.17)$ & $0.04(0.02)$ & $0.06(0.04)$ & $0.02(0.01$ & $8 \%$ & $17 \%$ & $4 \%$ \\
\hline & $\mathrm{D}(\mathrm{n}=18)$ & $0.05-0.14$ & $1.12(0.56)$ & $0.20(0.14)$ & $0.35(0.22)$ & $0.39(0.21)$ & $17 \%$ & $34 \%$ & $35 \%$ \\
\hline & & $0.14-0.42$ & $3.61(2.09)$ & $0.70(0.63)$ & $1.04(0.76)$ & $1.23(0.76)$ & $17 \%$ & $27 \%$ & $31 \%$ \\
\hline & & $0.42-1.2$ & $5.58(3.44)$ & $1.05(1.07)$ & $1.91(1.52)$ & $1.93(1.28)$ & $16 \%$ & $31 \%$ & $32 \%$ \\
\hline & & $1.2-3.5$ & $0.38(0.19)$ & $0.05(0.06)$ & $0.11(0.07)$ & $0.07(0.05)$ & $9 \%$ & $31 \%$ & $13 \%$ \\
\hline & & $3.5-10$ & $0.16(0.07)$ & $0.03(0.02)$ & $0.03(0.06)$ & $0.01(0.01)$ & $11 \%$ & $32 \%$ & $11 \%$ \\
\hline Transition & $\mathrm{N} / \mathrm{D}(\mathrm{n}=12)$ & $0.05-0.14$ & $0.47(0.19)$ & $0.13(0.07)$ & $0.18(0.08)$ & $0.12(0.05)$ & $24 \%$ & $37 \%$ & $26 \%$ \\
\hline & & $0.14-0.42$ & $1.33(0.56)$ & $0.32(0.17)$ & $0.37(0.15)$ & $0.32(0.14)$ & $21 \%$ & $28 \%$ & $24 \%$ \\
\hline & & $0.42-1.2$ & $2.87(1.44)$ & $0.46(0.37)$ & $0.74(0.44)$ & $0.61(0.34)$ & $14 \%$ & $25 \%$ & $21 \%$ \\
\hline & & $1.2-3.5$ & $0.37(0.14)$ & $0.11(0.04)$ & $0.13(0.06)$ & $0.04(0.02)$ & $28 \%$ & $37 \%$ & $12 \%$ \\
\hline & & $3.5-10$ & $0.25(0.15)$ & $0.07(0.02)$ & $0.07(0.01)$ & $0.01(0.00)$ & $24 \%$ & $29 \%$ & $4 \%$ \\
\hline & $N(n=4)$ & $0.05-0.14$ & $0.47(0.24)$ & $0.15(0.10)$ & $0.20(0.12)$ & $0.11(0.05)$ & $29 \%$ & $42 \%$ & $25 \%$ \\
\hline & & $0.14-0.42$ & $1.48(0.47)$ & $0.38(0.18)$ & $0.45(0.16)$ & $0.32(0.12)$ & $25 \%$ & $30 \%$ & $21 \%$ \\
\hline & & $0.42-1.2$ & $3.62(1.55)$ & $0.62(0.45)$ & $0.84(0.29)$ & $0.69(0.26)$ & $16 \%$ & $24 \%$ & $19 \%$ \\
\hline & & $1.2-3.5$ & $0.49(0.03)$ & $0.08(0.02)$ & $0.16(0.03)$ & $0.04(0.01)$ & $16 \%$ & $33 \%$ & $9 \%$ \\
\hline & & $3.5-10$ & $0.40(0.15)$ & $0.05(0.05)$ & $0.08(0.01)$ & $0.01(0.00)$ & $14 \%$ & $21 \%$ & $3 \%$ \\
\hline & $D(n=3)$ & $0.05-0.14$ & $0.32(0.12)$ & $0.02(0.02)$ & $0.11(0.05)$ & $0.09(0.04)$ & $12 \%$ & $34 \%$ & $27 \%$ \\
\hline & & $0.14-0.42$ & $0.84(0.18)$ & $0.06(0.07)$ & $0.24(0.06)$ & $0.22(0.06)$ & $14 \%$ & $29 \%$ & $26 \%$ \\
\hline & & $0.42-1.2$ & $1.58(0.34)$ & $0.12(0.04)$ & $0.32(0.08)$ & $0.31(0.08)$ & $7 \%$ & $20 \%$ & $19 \%$ \\
\hline & & $1.2-3.5$ & $0.22(0.04)$ & $0.00(0.00)$ & $0.06(0.02)$ & $0.02(0.01)$ & & $26 \%$ & $8 \%$ \\
\hline & & $3.5-10$ & $0.09(0.02)$ & $0.00(0.00)$ & $0.01(0.03)$ & $0.00(0.00)$ & & $51 \%$ & \\
\hline Wet period & $\mathrm{N} / \mathrm{D}(\mathrm{n}=5)$ & $0.05-0.14$ & $0.12(0.09)$ & $0.04(0.01)$ & $0.05(0.02)$ & $0.03(0.02)$ & $38 \%$ & $47 \%$ & $24 \%$ \\
\hline & & $0.14-0.42$ & $0.37(0.13)$ & $0.05(0.03)$ & $0.08(0.03)$ & $0.06(0.02)$ & $10 \%$ & $23 \%$ & $16 \%$ \\
\hline & & $0.42-1.2$ & $0.62(0.48)$ & $0.07(0.04)$ & $0.12(0.07)$ & $0.10(0.05)$ & $8 \%$ & $22 \%$ & $18 \%$ \\
\hline & & $1.2-3.5$ & $0.21(0.14)$ & $0.03(0.01)$ & $0.04(0.02)$ & $0.01(0.00)$ & $25 \%$ & $25 \%$ & $4 \%$ \\
\hline & & $3.5-10$ & $0.28(0.28)$ & $0.05(0.04)$ & $0.04(0.02)$ & $0.00(0.00)$ & $12 \%$ & $26 \%$ & $2 \%$ \\
\hline & $\mathrm{N}(\mathrm{n}=3)$ & $0.05-0.14$ & $0.18(0.10)$ & $0.05(0.01)$ & $0.06(0.02)$ & $0.04(0.02)$ & $29 \%$ & $35 \%$ & $21 \%$ \\
\hline & & $0.14-0.42$ & $0.46(0.07)$ & $0.06(0.02)$ & $0.10(0.01)$ & $0.07(0.02)$ & $13 \%$ & $21 \%$ & $16 \%$ \\
\hline & & $0.42-1.2$ & $0.91(0.40)$ & $0.09(0.03)$ & $0.16(0.04)$ & $0.13(0.02)$ & $10 \%$ & $19 \%$ & $16 \%$ \\
\hline & & $1.2-3.5$ & $0.29(0.11)$ & $0.01(0.02)$ & $0.05(0.01)$ & $0.01(0.00)$ & $13 \%$ & $19 \%$ & $4 \%$ \\
\hline & & $3.5-10$ & $0.43(0.28)$ & $0.05(0.04)$ & $0.06(0.02)$ & $0.00(0.00)$ & $11 \%$ & $15 \%$ & $2 \%$ \\
\hline & $\mathrm{D}(\mathrm{n}=2)$ & $0.05-0.14$ & $0.05(0.00)$ & $0.02(0.02)$ & $0.03(0.02)$ & $0.01(0.00)$ & $56 \%$ & $59 \%$ & $26 \%$ \\
\hline & & $0.14-0.42$ & $0.23(0.04)$ & $0.01(0.01)$ & $0.05(0.02)$ & $0.04(0.02)$ & $7 \%$ & $23 \%$ & $16 \%$ \\
\hline & & $0.42-1.2$ & $0.19(0.00)$ & $0.01(0.01)$ & $0.05(0.02)$ & $0.04(0.02)$ & $8 \%$ & $28 \%$ & $22 \%$ \\
\hline & & $1.2-3.5$ & $0.09(0.02)$ & $0.01(0.02)$ & $0.03(0.00)$ & $0.00(0.00)$ & $37 \%$ & $31 \%$ & \\
\hline & & $3.5-10$ & $0.06(0.01)$ & $0.00(0.00)$ & $0.02(0.00)$ & $0.00(0.00)$ & & $37 \%$ & \\
\hline
\end{tabular}

WSOC decreased steadily from the finest size range $(0.05-$ $0.14 \mu \mathrm{m})$ to the coarsest, although a mode in the range 1.2 $3.5 \mu \mathrm{m}$ was also observed in some samples from the transi- tion and wet periods. Table 3 also highlights some systematic differences in the composition of the aerosol samples collected at night-time compared to day-time. In particular, the 
$\mathrm{NC}$ fraction is significantly higher during the night (often by a factor of two compared to the day) in all periods. Conversely, PA are relatively more abundant during day in the dry period, but differences in the other two seasons are less evident. MDA also show limited diel variations, tending towards enrichment during night (similar to NC), especially in the finest size fraction during the transition period. The high content of neutral compounds of nocturnal samples is clearly correlated with the higher nocturnal concentrations observed for levoglucosan (Schkolnik et al., 2004). Therefore, the diel variations in the IC-UV composition can be interpreted in terms of different combustion conditions (e.g., smoldering vs. flaming processes) active at different times of the day. The production of PA during the day can also be explained by heterogeneous chemical processes promoted by sunlight (Hoffer et al., 2005. Although the chemical classes separated by the IC-UV method are not unambiguous tracers of the WSOC sources, the variations in their relative concentrations can be interpreted on the basis of the correlation with other chemical constituents of the aerosol (e.g., K), which can be more readily associated with a particular source or source processes. A full treatment of this subject is given in a parallel paper (Fuzzi et al., 2006 ${ }^{1}$ ).

The fraction of WSOC not accounted for by the sum of NC, MDA and PA is size-dependent, being around 0-15\% for the smallest particles, and increasing to $70 \%$ in the coarsest size range. The proportion is lower in the dry period, compared to the transition and especially the wet period, during which $50 \%$ of WSOC could not be accounted for even in the accumulation mode size range. The organic materials that can contribute to WSOC, especially in the wet period, and not accounted for by the IC-UV analysis could be either semi-volatile compounds that were lost during the calibration procedure, or hydrophilic colloids (very high molecular weight humic-like particles, fragments of biological membranes and other cell constituents) that are extracted from the impactor foils but escape analysis by HPLC.

\section{5 ${ }^{1}$ HNMR functional group composition}

${ }^{1}$ HNMR analysis provides the functional group composition of the mixture, but little information on the speciation into individual compounds. Furthermore, it does not provide information on the distribution of the functional groups into chemical classes. This explains why a pre-separation by preparative chromatography on DEAE columns was necessary to obtain the functional group compositions of NC, MDA and PA. ${ }^{1} \mathrm{HNMR}$ analysis in $\mathrm{D}_{2} \mathrm{O}$ solution provided direct measurements of the functional groups carrying hydrogen atoms bound to carbon atoms: a) alkylic groups $(\mathrm{CH})$; b) aliphatic groups bound to an unsaturated carbon atom (HC$\mathrm{C}=)$; c) alkoxyl groups (HC-O); d) acetal groups (O-CH-O) and e) aromatic groups $(\mathrm{HC}=)$. For the samples subjected to the derivatization procedure presented in Sect. 2.6, the concentration of $\mathrm{COOH}$ groups was also obtained. The com- plete results are discussed in the companion paper by Tagliavini et al. (2005). As a brief overview, we outline the following points: 1) significant differences were observed between the three periods as regards the composition of the fine particles, with the samples from the wet period exhibiting a lower content of aromatic groups and more unsaturated and hydroxylated aliphatic moieties; 2) the coarse fraction of the aerosol from the transition and wet periods, on the other hand, is dominated by oxygenated carbon atoms, indicating the occurrence of polyhydroxy-compounds; 3) carboxylic groups $(\mathrm{COOH})$ represent $13.3 \%, 19.7 \%$ and $18.4 \%$ of the water-soluble carbon accounted for by NMR analysis in fine aerosol samples collected during the dry, transition and wet periods, respectively; 4) when applied to sizesegregated samples, the functional group approach provides significantly different compositions in the $0.05-0.14 \mu \mathrm{m}$ size range compared to the $0.42-1.2 \mu \mathrm{m}$ range, the former containing much more alkyl and less oxygenated moieties; 5) the picture derived from IC separated fractions is consistent with what has been previously observed, i.e., that the neutral fraction is dominated by polyols (e.g., levoglucosan, mannitol), but still contains polyhydroxy and polyalkoxy benzenes; the mono-/diacids fraction can be seen as a mixture of hydroxylated alkyl and benzoic monocarboxylic and dicarboxylic acids, and the polyacidic fraction exhibits a humic-like character.

\section{Discussion}

\subsection{Speciated WSOC and chemical classes}

The analytical techniques described in the experimental section can be grouped into methods for individual compound analysis (GC-MS, IC and IEC-UV), and methods targeted to the separation of main chemical classes (IC-UV). The former allow the identification and measurement of six categories of polar organic compounds, but leave uncharacterized a substantial fraction of OC. Conversely, the IC-UV technique provides a high recovery in the measurement of the water-soluble fraction of OC by fractionation into three main categories, whose specific chemical compositions, however, rests poorly defined. Therefore, in general, the IC-UV chromatographic classes do not correspond directly to any of the categories of polyols and carboxylic acids accounted for by individual compound analyses, but are more likely to include them.

To better understand the chemical nature of the "neutral compounds", "mono-/diacids" and "polyacids", the WSOC speciated by GC-MS, IC and IEC in size-segregated samples can be classified according to their number of carboxylic groups per molecule; the estimation of their contribution to each of the three IC-UV classes is then straightforward. However, the concentrations of the identified WSOC were obtained on MOUDI samples, while those of total WSOC 
Table 4. Contribution of levoglucosan and carboxylic acids identified by IEC and IC, respectively, to total WSOC and neutral compounds (NC), mono-/diacids (MDA) and polyacids (PA) measured by the IC-UV method. The speciated carboxylic acids include $\mathrm{C}_{1}-\mathrm{C}_{3}$ aliphatic monocarboxylic acids (MCA), oxalic acid, $\mathrm{C}_{3}-\mathrm{C}_{9}$ aliphatic dicarboxylic acids (DCA), $\mathrm{C}_{7}-\mathrm{C}_{8}$ aromatic acids and $\mathrm{C}_{6}$ aliphatic tricarboxylic acids (TCA). Average mass balances were calculated on a carbon basis for the dry and transition periods, on the basis of a limited number of samples for which the MOUDI IFUSP and the five-stage Berner impactor were operated approximately in parallel. The concentrations of the polar organic compounds determined on the MOUDI samples by IEC and IC were converted into five-stage size-distributions for comparison with the total WSOC and NC, MDA and PA data, according to the procedure described in the text.

\begin{tabular}{|c|c|c|c|c|c|c|c|c|c|c|c|c|c|}
\hline & \multirow{3}{*}{$\begin{array}{l}\text { Size intervals } \\
\qquad(\mu \mathrm{m})\end{array}$} & \multirow{3}{*}{$\begin{array}{l}\text { Levoglu- } \\
\text { cosan }\end{array}$} & \multicolumn{5}{|c|}{$\%$ WSOC } & \multirow{3}{*}{$\begin{array}{c}\% \mathrm{NC} \\
\text { Levoglu- } \\
\text { cosan }\end{array}$} & \multirow{2}{*}{\multicolumn{3}{|c|}{$\begin{array}{c}\% \text { MDA } \\
\text { Aliphatic carboxylic acids }\end{array}$}} & \multirow{3}{*}{$\begin{array}{l}\text { Aromatic } \\
\text { acids }\end{array}$} & \multirow{3}{*}{$\begin{array}{c}\% \text { PA } \\
\text { Aliphatic } \\
\text { TCA }\end{array}$} \\
\hline & & & & Aliphatic & arboxylic acids & & Aromatic & & & & & & \\
\hline & & & MCA & Oxalic & $\mathrm{C}_{3}-\mathrm{C}_{9} \mathrm{DCA}$ & TCA & acids & & MCA & Oxalic & $\mathrm{C}_{3}-\mathrm{C}_{9} \mathrm{DCA}$ & & \\
\hline \multirow[t]{5}{*}{ Dry period } & $0.05-0.14$ & $0.3 \%$ & $0.3 \%$ & $0.5 \%$ & $0.5 \%$ & & $0.1 \%$ & $1.0 \%$ & $0.8 \%$ & $1.4 \%$ & $1.2 \%$ & $0.3 \%$ & \\
\hline & $0.14-0.42$ & $1.3 \%$ & $0.6 \%$ & $0.8 \%$ & $1.1 \%$ & $0.1 \%$ & $1.9 \%$ & $7.5 \%$ & $1.9 \%$ & $2.6 \%$ & $3.6 \%$ & $6.3 \%$ & $0.2 \%$ \\
\hline & $0.42-1.2$ & $2.7 \%$ & $1.1 \%$ & $1.3 \%$ & $1.6 \%$ & $0.1 \%$ & $1.6 \%$ & $12 \%$ & $3.1 \%$ & $3.5 \%$ & $4.4 \%$ & $4.3 \%$ & $0.3 \%$ \\
\hline & $1.2-3.5$ & $4.7 \%$ & $1.2 \%$ & $1.9 \%$ & $1.4 \%$ & $0.1 \%$ & $1.2 \%$ & $28 \%$ & $3.7 \%$ & $5.7 \%$ & $4.1 \%$ & $4.1 \%$ & $0.3 \%$ \\
\hline & $3.5-10$ & $0.0 \%$ & $1.0 \%$ & $1.8 \%$ & $0.9 \%$ & $0.1 \%$ & $2.6 \%$ & $0.1 \%$ & $0.6 \%$ & $1.0 \%$ & $0.7 \%$ & $2.1 \%$ & $1.6 \%$ \\
\hline \multirow{5}{*}{$\begin{array}{l}\text { Transition } \\
\text { period }\end{array}$} & $0.05-0.14$ & $0.2 \%$ & $0.4 \%$ & $0.2 \%$ & $0.4 \%$ & $0.1 \%$ & $0.2 \%$ & $0.6 \%$ & $1.0 \%$ & $0.9 \%$ & $1.0 \%$ & $0.6 \%$ & $0.3 \%$ \\
\hline & $0.14-0.42$ & $0.1 \%$ & $0.2 \%$ & $0.2 \%$ & $0.2 \%$ & $0.1 \%$ & $0.5 \%$ & $0.3 \%$ & $0.6 \%$ & $1.4 \%$ & $0.9 \%$ & $2.1 \%$ & $0.2 \%$ \\
\hline & $0.42-1.2$ & $2.2 \%$ & $0.9 \%$ & $0.7 \%$ & $1.4 \%$ & $0.2 \%$ & $1.1 \%$ & $13 \%$ & $3.0 \%$ & $4.5 \%$ & $4.6 \%$ & $3.7 \%$ & $0.7 \%$ \\
\hline & $1.2-3.5$ & $4.5 \%$ & $3.1 \%$ & $1.0 \%$ & $0.9 \%$ & $0.1 \%$ & $0.7 \%$ & $11 \%$ & $7.0 \%$ & $4.7 \%$ & $1.8 \%$ & $1.9 \%$ & $0.4 \%$ \\
\hline & $3.5-10$ & & $0.6 \%$ & $0.3 \%$ & $0.7 \%$ & $0.5 \%$ & $1.7 \%$ & & $2.1 \%$ & $2.5 \%$ & $2.8 \%$ & $7.1 \%$ & $10 \%$ \\
\hline
\end{tabular}

and of NC, MDA and PA were available only for the Berner impactor, making the comparison difficult owing to the different size resolutions and sampling efficiencies of the two impactors. To make the two sets of data comparable, we first defined a sub-set of four pairs of MOUDI IFUSP and Berner impactor (BI) samples that were collected approximately in parallel:

- MOUDI IFUSP 22 September 23:42 UT to 23 September 23:12 UT vs. BI 22 September 22:30 UT to 23 September 22:00 UT;

- MOUDI IFUSP 25 September 00:20 UT to 25 September 22:08 UT vs. BI 24 September 23:00 UT to 25 September 21:45 UT;

- MOUDIIFUSP 16 October 22:40 UT to 18 October 12:46 UT vs. BI 16 October 13:00 UT to 18 October 11:00 UT;

- MOUDI IFUSP 18 October 13:55 UT to 20 October 10:40 UT vs. BI 18 October 12:00 UT to 20 October 10:40 UT.

Then, the MOUDI size-distributions for the identified WSOC and inorganic compounds were converted to continuous sizedistributions according to an inversion algorithm, using the MICRON inversion program (Wolfenbarger and Seinfeld, 1990), which takes into account the collection efficiency and species concentration in each MOUDI stage. A more detailed description of the use of the program is given by Havránek et al. (1996). The concentrations of the chemical species measured in MOUDI samples could then be retrieved for the size intervals of the Berner impactor by integrating the continuous size distributions between the Berner cut-offs. To take into account the different sampling efficiencies of the two impactors, the concentrations of organic species were normalized to those of sulfate, which had been measured on both sets of impactor samples. The identified WSOC from MOUDI IFUSP were then expressed as $\mu \mathrm{gC} \mathrm{m}^{-3}$ and compared to the concentrations of total WSOC and of the IC-UV classes from the Berner impactor.

Table 4 shows the resulting average carbon budget for the dry period $(\mathrm{n}=2)$ and for the transition phase $(\mathrm{n}=2)$. Levoglucosan accounts for 1 to $12 \%$ of NC in the fine fraction, and for an even higher percentage in the size range $1.2-3.5 \mu \mathrm{m}$. Similarly, the identified mono- and di-carboxylic acids account for 6 to $16 \%$ of total MDA in the fine fraction, and $9-18 \%$ in coarse particles. In contrast, the contribution of the identified tricarboxylic acids (citric and tricarballylic) to total PA is very low, usually less than $1 \%$. In conclusion, the speciated WSOC represent around $1.5 \%$ of the total watersoluble carbon in the $0.05-0.14 \mu \mathrm{m}$ size interval, and up to $10 \%$ in the $0.42-3.5 \mu \mathrm{m}$ size range. The identified WSOC are mostly NC and MDA, while PA remains essentially uncharacterized at the molecular level. This finding supports the hypothesis that PA consist mostly of medium-to-high molecular weight compounds (HULIS). These results for the identified fractions of the three IC-UV classes analyzed in the impactor samples are in agreement with analogous data obtained on comparable $\mathrm{PM}_{2.5}$ samples collected during the 1999 LBA-EUSTACH-2 experiment (Mayol-Bracero et al., 2002a).

4.2 A synthetic representation of the WSOC composition by model compounds

In the previous section, the chemical characterization of the IC-UV chromatographic classes was attempted in terms of organic compounds identified at the molecular level, showing 

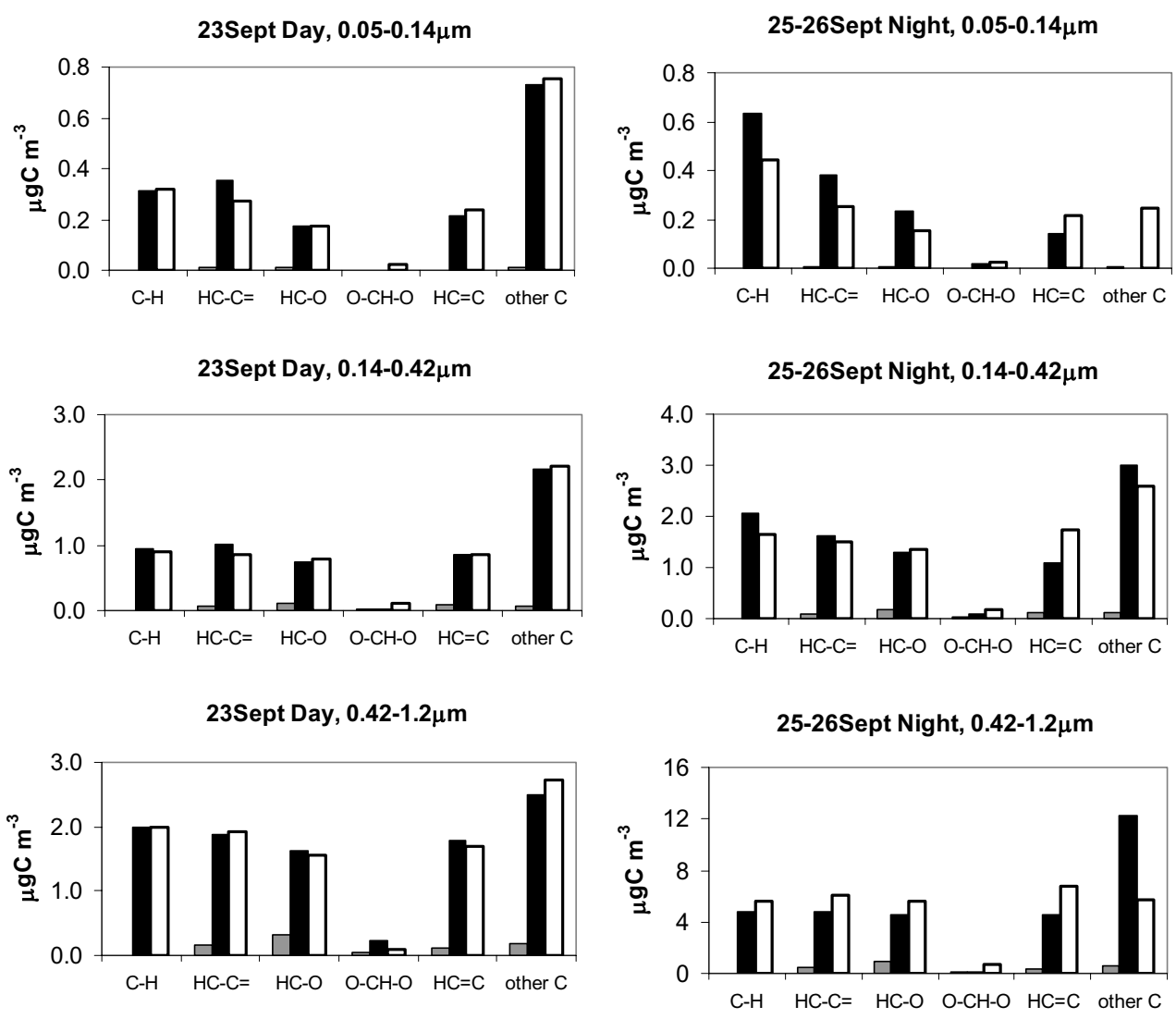

25-26Sept Night, 1.2-3.5 $\mu \mathrm{m}$

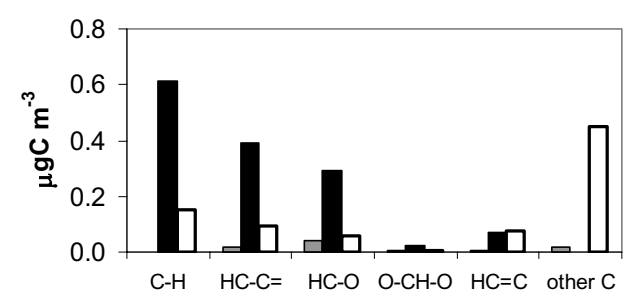

(a)

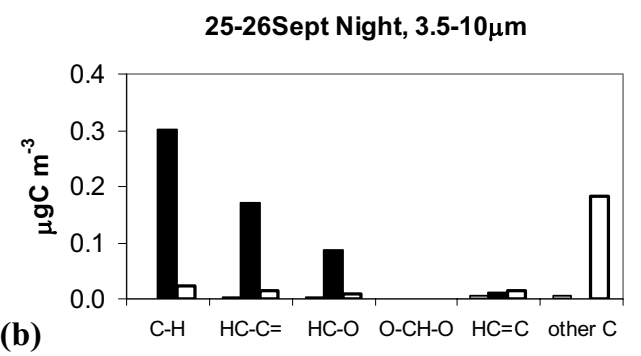

Fig. 5. Comparison between the functional group composition (black bars) determined by ${ }^{1} \mathrm{HNMR}$ analysis of size-segregated samples and HVDS2 $U_{\text {Gent }}$ filters and that reconstructed on the basis of the individual compounds identified by GC-MS, IC and IEC techniques (gray bars). WSOC functionalities of the mixtures of model compounds are also reported (white bars). The comparison is shown for the selected samples: (a, b) Two size-segregated samples from the dry period; (c) three $\mathrm{PM}_{2.5}$ HVDS samples from the dry, transition and wet periods, respectively; (d) chromatographic fractions of the $\mathrm{PM}_{2.5}$ HVDS sample collected on 25-26 September: NC (neutral compounds); MDA (mono-/diacids); PA (polyacids); (e) a coarse (PM>2.5) HVDS sample from the transition period. 


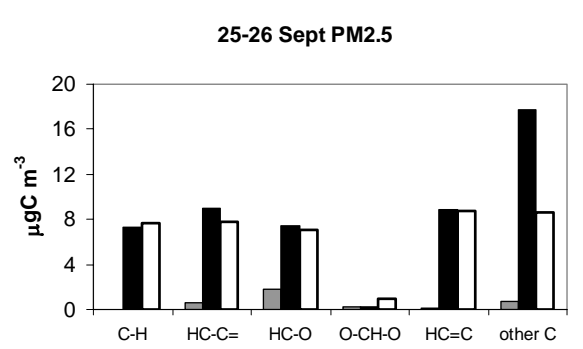

21-23 Oct PM2.5

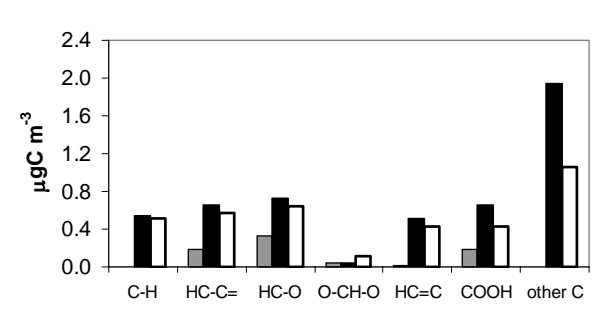

05-09 Nov PM2.5

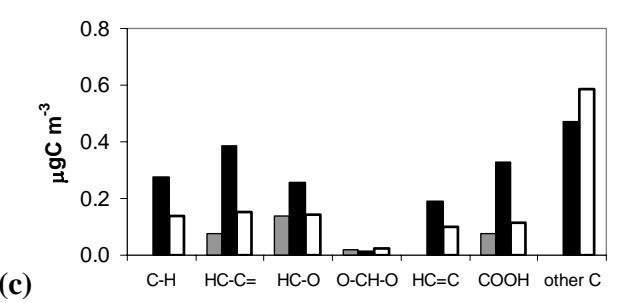

NC Fraction 25-26 Sept PM2.5

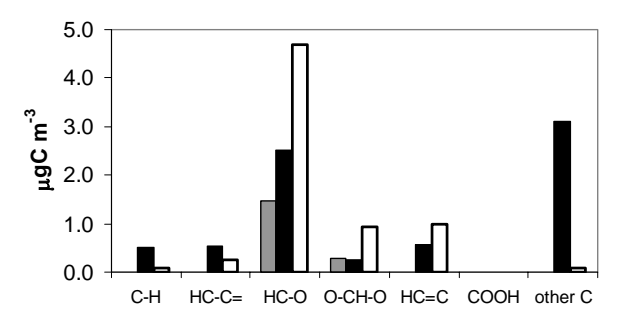

MDA Fraction 25-26 Sept PM2.5

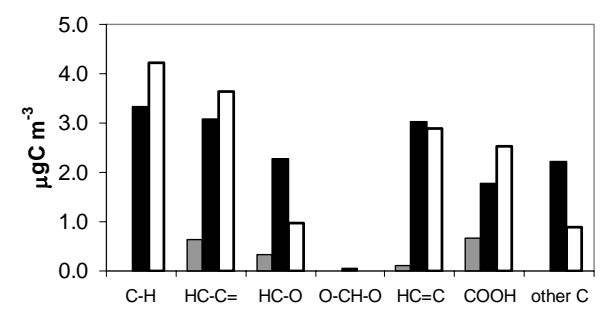

PA Fraction 25-26 Sept PM2.5

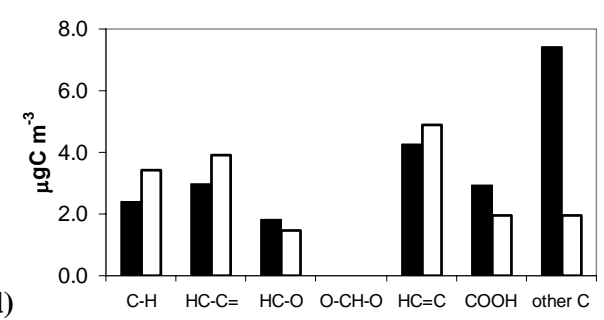

21-23 Oct PM10-PM2.5

(e)

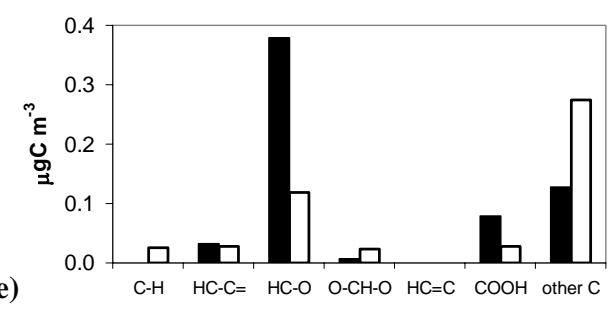

Fig. 5. Continued.

that large fractions of NC, MDA and especially PA could not be speciated using this approach. For the large fraction of the WSOC which eluded any speciation at the molecular level, only data on the neutral/acidic character and the average ${ }^{1}$ HNMR functional group composition could be obtained. Following the approach of Fuzzi et al. (2002), ${ }^{1}$ HNMR data and IC-UV fractionation can be exploited to provide at least a representation of the unidentified WSOC by a set of "model compounds". Model compounds are hypothetical that allow to reproduce the observed carbon content, functional group composition and other chemical properties of a mixture (or a fraction) of WSOC. The molecular formulae of the model compounds do not follow unequivocally from the functional group composition, but they are constrained by it. Using this approach the chemical composition of a mixture or a fraction of WSOC is represented in terms of a limited number of compounds, in cases where the speciation of organic compounds is not feasible, but a substantial pool of structural data and other information on the chemical properties of the mixture is however available. The main advantage of the representation through model compounds is that they can be directly used in microphysical models describing the physico-chemical properties of organic aerosols.

In a first step aimed at evaluation of model compounds, the functional group distributions characteristic of the unidentified WSOC were obtained from the available ${ }^{1} \mathrm{HNMR}$ 


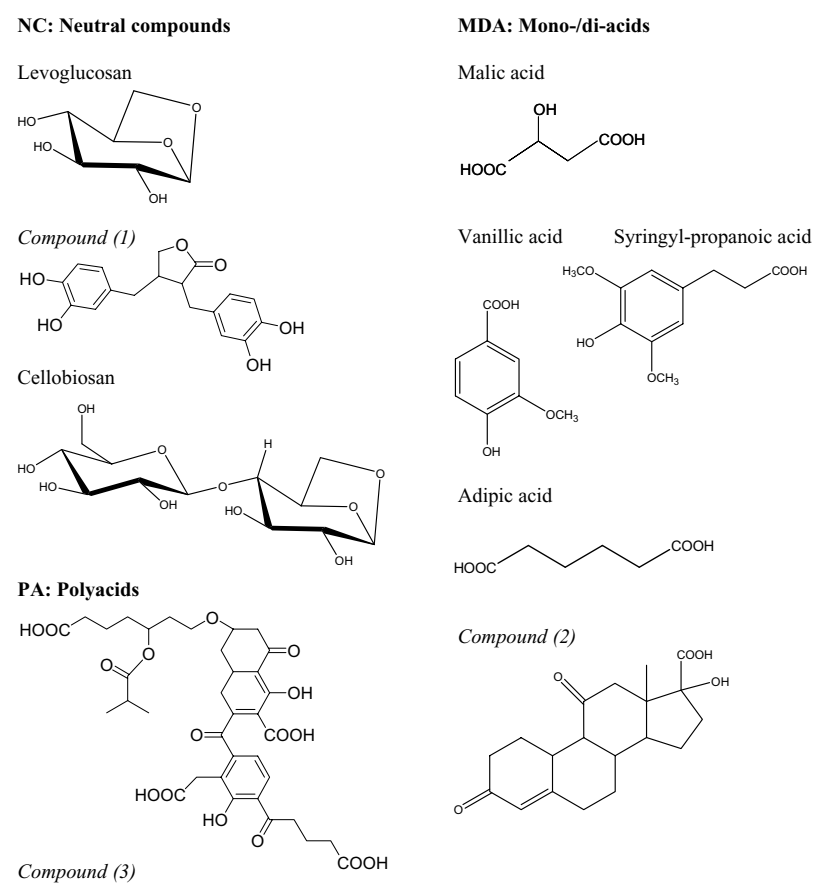

Fig. 6. Model compounds proposed to represent the chemical composition of WSOC on the basis of both speciation methods and functional group analysis. The three compounds labeled with numbers are hypothetical and not available commercially. On the basis of the chemical structure, they can be approximated to: the organic compound with CAS number 580-72-3 (Compound 1); the organic compound with CAS 53-06-5 (Compound 2); the Suwannee River fulvic acid (reference standard from IHSS).

compositions by the subtraction of the contribution of the individual compounds identified by GC-MS, IC and IEC. The contribution of the speciated compounds to the ${ }^{1} \mathrm{HNMR}$ composition was computed on the basis of their concentrations and molecular structure (e.g., anhydrosugars contain five $\mathrm{H}-\mathrm{C}-\mathrm{O}$ groups and one $\mathrm{O}-\mathrm{CH}-\mathrm{O}$ group per molecule, while malic acid contains one $\mathrm{HC}-(\mathrm{C}=)$, one $\mathrm{H}-\mathrm{C}-\mathrm{O}$ and two $\mathrm{COOH}$ groups). The calculation was performed for samples representative of the three periods of the campaign and for which ${ }^{1}$ HNMR data are available (Fig. 5): a, b) two Berner impactor samples from the dry period, one diurnal and one nocturnal; c) three $\mathrm{PM}_{2.5}$ HVDS2 ${ }_{\mathrm{UGent}}$ samples from the dry, transition and wet periods, respectively; and d) IC-UV fractions isolated from one $\mathrm{PM}_{2.5}$ HVDS2 2 Gent sample collected in the dry period. ${ }^{1} \mathrm{HNMR}$ data collected for these HVDS2 $2_{\text {UGent }}$ samples are compared in the figure to the functional groups accounted for by GC-MS $\mathrm{UA}_{\mathrm{A}}$ analysis of the HVDS1 $1_{\text {UGent }}$ samples collected exactly in parallel. By contrast, for the two impactor samples, the proportion of functional groups attributable to identified compounds was extrapolated from the average amount of WSOC accounted for by levoglucosan, MCA, DCA and aromatic acids in the dry period (Table 4). In general, $\mathrm{COOH}$ and $\mathrm{H}-\mathrm{C}-\mathrm{O}$ groups are the functional groups for which the individual compound analysis provides the best recoveries. Conversely, there is a large amount of water-soluble carbon occurring as aliphatic and aromatic $\mathrm{C}-\mathrm{H}$ groups that cannot be covered by the available set of speciated organic compounds, and for which only a representation through model compounds is possible.

A minimum of six model compounds aimed to represent the unspeciated WSOC was necessary to explain the observed variability in the functional group composition of the samples. The molecular structure of the model compounds and their relative concentrations were chosen in order to match as closely as possible the chemical composition of the samples in Fig. 5 with respect to the functional groups (from ${ }^{1} \mathrm{HNMR}$ characterization) and main chemical classes (NC, MDA and PA from IC-UV analysis), as shown in Table 5 for the example of the 23 September impactor sample. This sample was used to provide the model WSOC chemical composition for the dry period (daytime). The WSOC fraction accounted for by molecular speciation was expressed by the three model compounds, "levoglucosan", "malic acid" and "vanillic acid", introduced respectively as proxies of: a) the speciated polyhydroxylated compounds (anhydrosugars, sugar-alcohols, saccharides, 2-methyltetrols), b) the identified $\mathrm{C}_{1}-\mathrm{C}_{9}$ aliphatic mono- and dicarboxylic acids, and c) the identified aromatic acids ${ }^{3,4}$. Their concentrations relative to that of total WSOC were set fixed to the values reported in Table 4. Provided that the total concentrations of neutral compounds, mono-/di-acids and polyacids in the chemical model correspond to those determined by IC-UV analysis, the chemical structure and relative concentrations of the model compounds representing the WSOC fraction eluding molecular speciation were varied in an iterative process, until the functional group composition of the mixture reached good agreement with that measured by ${ }^{1} \mathrm{HNMR}$ analysis. In the case of the chemical model evaluated for the dry period (night-time), the functional group composition of model neutral species (levoglucosan+compound 2+cellobiosan), mono/diacids (malic acid+vanillic acid+compound 3+syringyl propanoic acid+adipic acid) and polyacids (compound 3) was also validated against the ${ }^{1} \mathrm{HNMR}$ functional group compositions obtained for the three chromatographic fractions of the nocturnal sample collected on 25-26 September

\footnotetext{
${ }^{3}$ No specific class for the identified tricarboxylic acids was introduced because of their very low contribution to PA.

${ }^{4}$ As regards the wet period samples, size-segregated data for the contribution of model compounds "levoglucosan" and "malic acid" to WSOC were extrapolated from the average data for the transition period (Table 4), while the contribution of "vanillic acid" was set to zero. This is qualitatively in agreement with Fig. 3, showing that low-molecular weight aromatic compounds were not detected in the wet period, and that, despite the decrease of anhydrosugars, the content of polyhydroxylated compounds in the fine fraction of PM decreased only slightly from the transition to the wet period, due to the simultaneous increase of the 2-methyltetrol concentrations.
} 
(Fig. 5d). The functional groups of the model compounds constrained by the ${ }^{1} \mathrm{HNMR}$ measurements were the alkyl (C$\mathrm{H})$, unsaturated aliphatic $(\mathrm{HC}-\mathrm{C}=)$, alkoxyl $(\mathrm{HC}-\mathrm{O})$, acetal $(\mathrm{O}-\mathrm{CH}-\mathrm{O})$ and aromatic $(\mathrm{HC}=)$ groups, plus, in the case of HVDS samples, carboxyl groups $(\mathrm{COOH})$.

The resulting WSOC model compounds are shown in Fig. 6. Beside the three proxies of the compounds identified at the molecular level, two surrogates were introduced for the unidentified neutral species, three for the unidentified mono-/diacids and one for the polyacids:

- Cellobiosan accounts for the unidentified polyhydroxylated compounds. The occurrence of oligomers of anhydrosugars in biomass smoke was suggested by Gao et al. (2003).

- "Compound (1)", a compound close to matairesinol, a plant phenolic compound that has also been found in biomass smoke (Simoneit et al., 2003), reproduces the aromatic and $\mathrm{H}-\mathrm{C}-\mathrm{C}=$ groups of the $\mathrm{NC}$.

- Adipic acid, a $\mathrm{C}_{6}$ aliphatic dicarboxylic acid, accounts for the excess $\mathrm{COOH}$ groups determined by the derivatization-NMR technique.

- Syringyl-propionic acid (Nolte et al., 2001), a methoxylated $\mathrm{C}_{11}$ aromatic acid representing the unidentified aromatic species.

- "Compound (2)", a hypothetical $\mathrm{C}_{19}$ aliphatic monocarboxylic acid, which reproduces the abundance of saturated aliphatic moieties determined by ${ }^{1} \mathrm{HNMR}$, especially in the $0.05-0.14$ and $3.5-10 \mu \mathrm{m}$ size intervals of the nocturnal sample from the dry season. Acyclic compounds like compound (2) have previously been reported for biomass smoke particles (Simoneit et al., $\left.2003^{5}\right)$.

- The polyacidic fraction is represented in all samples by the same single species, "Compound (3)", a fulviclike substance. This is a hypothetical compound, whose structure is based on the functional group composition of the polyacidic fraction of sample HVDS2 ${ }_{\text {UGent }}$ collected on 25-26 September (Fig. 5d). It resembles that of the Suwannee River fulvic acid (Averett et al., 1989), but is less aromatic while showing more saturated aliphatic moieties. Therefore, the choice of the Suwannee River fulvic reference material to reproduce the chemical properties of the PA fraction in laboratory

\footnotetext{
${ }^{5}$ In this study, the acyclic compounds were found prevalently in the water-insoluble fraction. Compound (2) must exhibit a limited solubility in water, probably higher than that of cortisone, a compound with similar structure but with no carboxylic groups and a water solubility of $0.28 \mathrm{~g} / \mathrm{kg} \mathrm{H} \mathrm{H}_{2} \mathrm{O}$. This solubility can be sufficient for the extraction of compound (2)-like WSOC, for which a minimum amount of water of $15 \mathrm{~g}$ per $0.1 \mathrm{mgC}$ of sample was always used.
}

experiments cannot be considered as optimal, although it is still preferable to the other commercial standards of humic substances or of other high-molecular weight water-soluble substances.

It is noted that the resulting model NC composition lacks the saturated aliphatic moieties observed in the samples, for which a suitable candidate molecule could not be found. Therefore, the closure of the observed functional group composition of NC could be only partially achieved (Fig. 5d).

The composition of the mixture of model compounds simulating the functional group composition of the 23 September BI sample is reported in Table 5, while the comparison with the NMR data is graphically shown in Fig. 5a. The simulated functional group compositions for the other samples from the various periods of the campaign is also shown in Figs. 5b, c, e. The composition of the mixtures of model compounds used in each case is reported in Table 6, expressed using mass fractions of each compound in the mixtures. Figure 5 shows that good agreement is reached for fine aerosol samples from the dry and the transition period (Fig. 5c), for the size-segregated composition of the 23 September BI sample (Fig. 5a) and for the 25-26 September BI sample in the submicron size range (accounting for most of the PM). By increasing the proportion of the aliphatic carboxylic acid "Compound 2" in the coarse size range of the BI sample collected on 25-26 September, we could reproduce the observed increase of aliphatic groups only to a limited extent (Fig. 5b). In the case of the $\mathrm{PM}_{2.5}$ sample from the wet period (Fig. $5 \mathrm{c}$ ), the WSOC fraction recovered by the IC-UV method and represented through model compounds could not account for the total functional groups estimated by ${ }^{1} \mathrm{HNMR}$. Therefore, only a relative functional group composition could be reproduced. Finally, the ${ }^{1}$ HNMR composition of the HVDS coarse filter (Fig. 5e) shows a very high content of hydroxyl groups, which could not be fully accounted for by the model polyhydroxylated neutral compounds.

The above paragraphs describe how to evaluate model WSOC compositions constrained by ${ }^{1} \mathrm{HNMR}$ data and the IC-UV grouping method. As a final remark, it should be emphasized that the molecular weight of the model compounds representing the (large) fraction of WSOC not speciated at the molecular level cannot be constrained by the present approach. It can be assumed that the derivatization-GC-MS and ion chromatography methods were rather efficient in the determination of the low-molecular weight fraction of WSOC. Consequently, the model compounds introduced to represent the uncharacterized fraction must include medium-high molecular weight species. In the model presented here, the compounds with molecular weight higher than 300 account for $60-70 \%$ of WSOC in the fine fraction, consistent with the results of EGA analysis, which indicates a fraction of $60-80 \%$ on the basis of the thermal evolution behavior. The maximum molecular weight attributable to the model compounds reproducing the more refractory fraction of WSOC 
Table 5. Example of model composition of WSOC constrained by chromatographic and spectroscopic analysis of a size-segregated aerosol sample. The composition of the three size intervals corresponding to the Berner impactor stages collecting the fine fraction of the aerosol is shown. The TOC and IC-UV analyses as well as the ${ }^{1}$ HNMR data refer to the dry period sample collected on 23 September in daytime. The IC-UV classes are: NC (neutral compounds), MDA (mono-/diacids) and PA (polyacids), while UR is the unrecovered WSOC fraction. The classes of compounds speciated at the molecular level are here represented by three proxies: levoglucosan (LGS), malic acid (MA) and vanillic acid (VA). Their concentration relative to total WSOC was derived from Table 4. All data obtained by the chemical analyses are reported in italics in the table. The model compounds introduced to represent the WSOC recovered by the IC-UV techniques but not speciated at the molecular level are: Compound 1 (C1), cellobiosan (CBS), syringyl-propanoic acid (SPA), Compound 2 (C2), adipic acid (AD), Compound 3 (C3) (Fig. 6). Table 5a shows that the proportions of the model neutral species, mono-/diacids and polyacids, are set fixed to those determined by IC-UV analysis. The concentrations of the model compounds (bottom of Table 5a) and their specific functional groups (upper part of Table 5b) are then used to simulate the WSOC functional group composition (column labeled "total" in Table 5b) to be validated against the measured ${ }^{1}$ HNMR composition (right column of Table $5 b$ ). ${ }^{\dagger}$ Simulated total "other C" (i.e., the functional groups that cannot be detected by ${ }^{1} \mathrm{HNMR}$ analysis) includes the "other C" of the model compounds plus the carbon not recovered (UR) by the IC-UV analysis.

\begin{tabular}{|c|c|c|c|c|c|c|c|c|c|c|c|}
\hline \multicolumn{12}{|c|}{ Composition of the mixture of model compounds (\% WSOC) } \\
\hline size range $(\mu \mathrm{m})$ & & LGS & $\mathrm{C} 1$ & CBS & MA & VA & $\mathrm{C} 2$ & SPA & $\mathrm{AD}$ & $\mathrm{C} 3$ & \\
\hline $0.05-0.14$ & & $0.3 \%$ & $2.0 \%$ & $7.1 \%$ & $1.3 \%$ & $0.1 \%$ & $15.4 \%$ & $2.9 \%$ & $11.6 \%$ & $32 \%$ & \\
\hline $0.14-0.42$ & & $1.3 \%$ & $3.1 \%$ & $10.4 \%$ & $2.5 \%$ & $1.9 \%$ & $11.8 \%$ & $2.6 \%$ & $10.2 \%$ & $32 \%$ & \\
\hline $0.42-1.2$ & & $2.7 \%$ & $3.6 \%$ & $10.7 \%$ & $4.0 \%$ & $1.6 \%$ & $15.9 \%$ & $3.1 \%$ & $12.4 \%$ & $39 \%$ & \\
\hline \multicolumn{12}{|c|}{ Concentration of the organic fractions $\left(\mu \mathrm{g} \mathrm{C} \mathrm{m}^{-3}\right)$ from TOC and IC-UV analysis } \\
\hline $0.05-0.14$ & 1.78 & 0.17 & & & 0.56 & & & & & 0.57 & 0.49 \\
\hline $0.14-0.42$ & 5.76 & 0.86 & & & 1.67 & & & & & 1.86 & 1.37 \\
\hline $0.42-1.2$ & 9.97 & 1.69 & & & 3.69 & & & & & 3.93 & 0.66 \\
\hline \multicolumn{12}{|c|}{ Concentrations of the model compounds $\left(\mu \mathrm{g} \mathrm{Cm}^{-3}\right)$} \\
\hline size range $(\mu \mathrm{m})$ & & LGS & $\mathrm{C} 1$ & CBS & MA & VA & $\mathrm{C} 2$ & SPA & $\mathrm{AD}$ & C3 & \\
\hline $0.05-0.14$ & & 0.005 & 0.035 & 0.127 & 0.023 & 0.002 & 0.275 & 0.052 & 0.207 & 0.569 & \\
\hline $0.14-0.42$ & & 0.076 & 0.180 & 0.600 & 0.144 & 0.109 & 0.679 & 0.147 & 0.588 & 1.859 & \\
\hline $0.42-1.2$ & & 0.266 & 0.356 & 1.072 & 0.399 & 0.160 & 1.586 & 0.308 & 1.234 & 3.930 & \\
\hline
\end{tabular}

\begin{tabular}{|c|c|c|c|c|c|c|c|c|c|c|c|c|}
\hline \multicolumn{13}{|c|}{ Functional groups breakdown of model compounds } \\
\hline & & LGS & $\mathrm{C} 1$ & CBS & MA & VA & $\mathrm{C} 2$ & SPA & $\mathrm{AD}$ & \multicolumn{2}{|l|}{$\mathrm{C} 3$} & \\
\hline & C-H & & $1 / 18$ & & & & $10 / 20$ & & $2 / 6$ & $7 / 36$ & & \\
\hline & $\mathrm{HC}-\mathrm{C}=$ & & $3 / 18$ & & $2 / 5$ & & $4 / 20$ & $2 / 11$ & $2 / 6$ & $8 / 36$ & & \\
\hline & $\mathrm{HC}-\mathrm{O}$ & $5 / 6$ & $1 / 18$ & $10 / 12$ & $1 / 5$ & $1 / 8$ & & $2 / 11$ & & $3 / 36$ & & \\
\hline & $\mathrm{O}-\mathrm{CH}-\mathrm{O}$ & $1 / 6$ & & $2 / 12$ & & & & & & & & \\
\hline & $\mathrm{HC}=\mathrm{C}$ & & $12 / 18$ & & & $6 / 8$ & $2 / 20$ & $6 / 11$ & & $10 / 36$ & & \\
\hline & other $\mathrm{C}$ & & $1 / 18$ & & $2 / 5$ & $1 / 8$ & $4 / 20$ & $1 / 11$ & $2 / 6$ & $8 / 36$ & & \\
\hline \multicolumn{12}{|c|}{ Functional groups concentrations $\left(\mu \mathrm{g} \mathrm{C} \mathrm{m}^{-3}\right)$ of model compounds } & NMR functional groups \\
\hline size range $(\mu \mathrm{m})$ & & LGS & $\mathrm{C} 1$ & CBS & MA & VA & $\mathrm{C} 2$ & SPA & $\mathrm{AD}$ & $\mathrm{C} 3$ & total & $\left(\mu \mathrm{g} \mathrm{C} \mathrm{m}^{-3}\right)$ \\
\hline \multirow[t]{6}{*}{$0.05-0.14$} & C-H & & 0.002 & & & & 0.137 & & 0.069 & 0.111 & 0.319 & 0.310 \\
\hline & $\mathrm{HC}-\mathrm{C}=$ & & 0.006 & & 0.009 & & 0.055 & 0.009 & 0.069 & 0.126 & 0.275 & 0.356 \\
\hline & HC-O & 0.004 & 0.002 & 0.106 & 0.005 & 0.000 & & 0.009 & & 0.047 & 0.174 & 0.175 \\
\hline & $\mathrm{O}-\mathrm{CH}-\mathrm{O}$ & 0.001 & & 0.021 & & & & & & & 0.022 & \\
\hline & $\mathrm{HC}=\mathrm{C}$ & & 0.023 & & & 0.001 & 0.027 & 0.028 & & 0.158 & 0.238 & 0.212 \\
\hline & other $\mathrm{C}$ & & 0.002 & & 0.009 & 0.000 & 0.055 & 0.005 & 0.069 & 0.126 & $0.757^{\dagger}$ & 0.730 \\
\hline \multirow[t]{6}{*}{$0.14-0.42$} & C-H & & 0.010 & & & & 0.340 & & 0.196 & 0.362 & 0.907 & 0.941 \\
\hline & $\mathrm{HC}-\mathrm{C}=$ & & 0.030 & & 0.058 & & 0.136 & 0.027 & 0.196 & 0.413 & 0.859 & 1.022 \\
\hline & $\mathrm{HC}-\mathrm{O}$ & 0.063 & 0.010 & 0.500 & 0.029 & 0.014 & & 0.027 & & 0.155 & 0.798 & 0.749 \\
\hline & $\mathrm{O}-\mathrm{CH}-\mathrm{O}$ & 0.013 & & 0.100 & & & & & & & 0.113 & 0.031 \\
\hline & $\mathrm{HC}=\mathrm{C}$ & & 0.120 & & & 0.082 & 0.068 & 0.080 & & 0.516 & 0.866 & 0.853 \\
\hline & other $\mathrm{C}$ & & 0.010 & & 0.058 & 0.014 & 0.136 & 0.013 & 0.196 & 0.413 & $2.213^{\dagger}$ & 2.159 \\
\hline \multirow[t]{6}{*}{$0.42-1.2$} & C-H & & 0.020 & & & & 0.793 & & 0.411 & 0.764 & 1.988 & 1.989 \\
\hline & $\mathrm{HC}-\mathrm{C}=$ & & 0.059 & & 0.160 & & 0.317 & 0.056 & 0.411 & 0.873 & 1.877 & 1.928 \\
\hline & HC-O & 0.222 & 0.020 & 0.893 & 0.080 & 0.020 & & 0.056 & & 0.327 & 1.618 & 1.547 \\
\hline & $\mathrm{O}-\mathrm{CH}-\mathrm{O}$ & 0.044 & & 0.179 & & & & & & & 0.223 & 0.100 \\
\hline & $\mathrm{HC}=\mathrm{C}$ & & 0.237 & & & 0.120 & 0.159 & 0.168 & & 1.092 & 1.775 & 1.685 \\
\hline & other C & & 0.020 & & 0.160 & 0.020 & 0.317 & 0.028 & 0.411 & 0.873 & $2.491^{\dagger}$ & 2.722 \\
\hline
\end{tabular}


Table 6. Model composition of water-soluble carbon in size-segregated samples from the different periods of the SMOCC campaign. Model compounds with underscored names were evaluated on the basis of WSOC speciation, while the others were based only on functional group analysis and the apportionment of WSOC into the three main chemical classes from the IC-UV method: neutral compounds (NC), mono/diacids (MDA) and polyacids (PA). Model compounds corresponding to organic species never detected in aerosol samples are hypothetical compounds labeled with numbers 1 to 3 in the table. Their structure is shown in Fig. 6, and recommendations for suitable surrogates among the commercial standards are given in the footnotes.

\begin{tabular}{|c|c|c|c|c|c|c|c|c|c|c|c|c|c|c|c|c|c|}
\hline \multirow{2}{*}{\multicolumn{3}{|c|}{ Size range $(\mu \mathrm{m})$}} & \multicolumn{3}{|c|}{ Dry (day) } & \multicolumn{3}{|c|}{ Dry (night) } & \multicolumn{2}{|c|}{ Dry (day/night) } & \multicolumn{3}{|c|}{ Transition } & \multicolumn{3}{|c|}{ Wet } & \multirow{2}{*}{$\begin{array}{c}\text { Transition/ } \\
\text { Wet } \\
1.2-10\end{array}$} \\
\hline & & & $0.05-0.14$ & $0.14-0.42$ & $0.42-1.2$ & $0.05-0.14$ & $0.14-0.42$ & $0.42-1.2$ & $1.2-3.5$ & $3.5-10$ & $0.05-0.14$ & $0.14-0.42$ & $0.42-1.2$ & $0.05-0.14$ & $0.14-0.42$ & $0.42-1.2$ & \\
\hline \multirow{3}{*}{$\mathrm{NC}$} & levoglucosan & $\mathrm{C}_{6} \mathrm{H}_{10} \mathrm{O}_{5}$ & $0.5 \%$ & $2.1 \%$ & $3.4 \%$ & $0.4 \%$ & $1.9 \%$ & $3.2 \%$ & $10.7 \%$ & $0.2 \%$ & $0.2 \%$ & $0.1 \%$ & $3.9 \%$ & $0.3 \%$ & $0.1 \%$ & $4.4 \%$ & $18.5 \%$ \\
\hline & $\overline{\text { compound } 1^{a}}$ & $\mathrm{C}_{18} \mathrm{H}_{22} \mathrm{O}_{6}$ & $2.3 \%$ & $3.4 \%$ & $3.2 \%$ & $2.5 \%$ & $3.0 \%$ & $3.1 \%$ & $5.7 \%$ & $4.1 \%$ & $6.0 \%$ & $6.8 \%$ & $4.8 \%$ & $5.1 \%$ & $5.4 \%$ & $4.5 \%$ & $0.0 \%$ \\
\hline & cellobiosan & $\mathrm{C}_{12} \mathrm{H}_{20} \mathrm{O}_{10}$ & $12.0 \%$ & $16.4 \%$ & $13.8 \%$ & $13.1 \%$ & $14.5 \%$ & $13.8 \%$ & $2.9 \%$ & $9.7 \%$ & $27.3 \%$ & $30.9 \%$ & $18.2 \%$ & $23.1 \%$ & $24.6 \%$ & $16.4 \%$ & $46.5 \%$ \\
\hline \multirow{4}{*}{ MDA } & malic acid & $\mathrm{C}_{4} \mathrm{H}_{6} \mathrm{O}_{5}$ & $2.7 \%$ & $4.9 \%$ & $6.3 \%$ & $2.2 \%$ & $4.4 \%$ & $5.9 \%$ & $12.8 \%$ & $18.1 \%$ & $1.5 \%$ & $1.0 \%$ & $6.4 \%$ & $2.2 \%$ & $1.6 \%$ & $7.3 \%$ & $4.2 \%$ \\
\hline & vanillic acid & $\mathrm{C}_{8} \mathrm{H}_{8} \mathrm{O}_{4}$ & $0.1 \%$ & $2.3 \%$ & $1.6 \%$ & $0.1 \%$ & $2.1 \%$ & $1.5 \%$ & $2.1 \%$ & $8.0 \%$ & $0.2 \%$ & $0.5 \%$ & $1.5 \%$ & $0.0 \%$ & $0.0 \%$ & $0.0 \%$ & $0.0 \%$ \\
\hline & $\overline{\text { adipic acid }}$ & $\mathrm{C}_{6} \mathrm{H}_{10} \mathrm{O}_{4}$ & $17.7 \%$ & $14.4 \%$ & $14.3 \%$ & $2.4 \%$ & $10.2 \%$ & $10.7 \%$ & $0.0 \%$ & $0.0 \%$ & $33.6 \%$ & $32.7 \%$ & $30.3 \%$ & $35.3 \%$ & $34.3 \%$ & $32.5 \%$ & $30.8 \%$ \\
\hline & $\begin{array}{l}\text { syringyl- } \\
\text { propionic acid }\end{array}$ & $\mathrm{C}_{11} \mathrm{H}_{14} \mathrm{O}_{5}$ & $3.7 \%$ & $3.0 \%$ & $3.0 \%$ & $1.7 \%$ & $10.1 \%$ & $7.2 \%$ & $0.0 \%$ & $0.0 \%$ & $2.4 \%$ & $2.2 \%$ & $2.1 \%$ & $0.0 \%$ & $0.0 \%$ & $0.0 \%$ & $0.0 \%$ \\
\hline & compound $2^{b}$ & $\mathrm{C}_{19} \mathrm{H}_{24} \mathrm{O}_{5}$ & $16.7 \%$ & $11.9 \%$ & $13.0 \%$ & $45.7 \%$ & $16.6 \%$ & $8.9 \%$ & $46.4 \%$ & $43.0 \%$ & $3.5 \%$ & $3.2 \%$ & $3.0 \%$ & $2.8 \%$ & $2.4 \%$ & $2.4 \%$ & $0.0 \%$ \\
\hline PA & compound $3^{\mathrm{c}}$ & $\mathrm{C}_{36} \mathrm{H}_{42} \mathrm{O}_{16}$ & $44.3 \%$ & $41.6 \%$ & $41.4 \%$ & $32.0 \%$ & $37.2 \%$ & $45.8 \%$ & $19.2 \%$ & $16.9 \%$ & $25.2 \%$ & $22.7 \%$ & $29.8 \%$ & $31.2 \%$ & $31.6 \%$ & $32.5 \%$ & $0.0 \%$ \\
\hline
\end{tabular}

${ }^{a}$ Can be approximated to compound with CAS 580-72-3;

${ }^{\mathrm{b}}$ Can be approximated to compound with CAS 53-06-5

${ }^{\mathrm{c}}$ Can be approximated to the Suwannee River fulvic acid (reference standard from IHSS).

cannot be determined accurately. However, it cannot be very high for the less polar compounds, like compounds (1) and (2), whose homologs with 30 carbon atoms would probably be insoluble even in the large excess of water used for extraction of the samples. Conversely, the polyhydroxylated species with more than six carbon atoms, represented in the model by cellobiosan, can be perfectly soluble even when occurring in very large polymeric forms. Although polyhydroxylated compounds larger than cellobiosan have not yet been found in samples of ambient aerosol, such polymers may form in wood smoke (Kawamoto et al., 2003), and therefore the molecular weight of the WSOC fraction represented by the model compound "cellobiosan" remains largely uncertain.

The list of model compounds representative of the WSOC composition in the aerosol samples collected during the SMOCC campaign is more complex than that presented in the previous work by Fuzzi et al. (2001), based on samples from the Po Valley. In contrast to the former study, a more detailed picture of the low-molecular weight WSOC emerged from the GC-MS and IC analyses performed during the LBA-SMOCC experiment. The identified species are represented by distinct model compounds (levoglucosan, malic acid and vanillic acid). They constitute a subset of model compounds known with a higher confidence, whereas the remaining unidentified compounds are more susceptible to modifications following different approaches in defining the chemical classes, and improvements in the characterization of un-speciated WSOC. For this reason, it is thought that the current representation is more flexible and provides a better integration of the information from the individual compound analysis with the results from the functional group characterization.

\section{Conclusions}

During the LBA-SMOCC field campaign, biomass burning emissions frequently caused episodes of very high concentrations of submicron carbonaceous aerosol (submicron TC concentrations $>50 \mu \mathrm{gC} \mathrm{m}^{-3}$ ) in the period 9 September8 October 2002, while at the beginning of November, after the end of the intense burning period, the measured submicron TC concentrations were 20 times lower. At the same time, biogenic sources produced a constant background of aerosol throughout the campaign, which was found predominantly in the coarse mass fraction. Fine and coarse aerosol TC differ also with respect to their water-soluble fraction, which is $64 \%$ on average in the first case and only $34 \%$ in the latter. The EC accounted for $12 \%$ on average of TC in the fine fraction of the aerosol. A unique combination of analytical techniques for individual compound analysis was employed to speciate the aerosol organic compounds, resulting in the apportionment of up to $8 \%$ of the submicron TC (ca. $11 \%$ of WSOC). Carboxylic acids and polyhydroxylated compounds, comprising both pyrogenic and biogenic species, were the main classes of compounds speciated. Pyrogenic compounds include anhydrosugars, aromatic acids and aldehydes, while biogenic species include sugars, sugaralcohols, 2-methyltetrols and malic acid. The ratio between total identified pyrogenic and biogenic compounds changed from 10:1 in the dry period to 1:3 in the wet period, showing that biomass burning was still active at the end of the field campaign.

Three main chemical classes of WSOC isolated by the IC-UV method (i.e., neutral compounds, mono-/diacids and polyacids) were detected in size-segregated aerosol samples throughout the campaign, although the concentrations 
of polyacids were low in the coarse fraction, especially at the onset of the wet period. The speciated polyhydroxylated compounds and low-molecular weight carboxylic acids contributed $1-20 \%$ to both, neutral compounds and mono/diacids. Conversely, the polyacidic fraction remained almost entirely uncharacterized at the molecular level. An insight into the unresolved fraction of WSOC was provided by ${ }^{1}$ HNMR functional group analysis, showing that most of the less polar compounds, characterized by extended saturated aliphatic and aromatic moieties, escaped molecular speciation.

The size-segregated composition of WSOC was summarized by a set of model compounds, which reproduce both the composition of the identified organic compounds and the functional groups of the whole WSOC mixture. The model compounds retain the average structural information on WSOC derived by the chemical characterization. The main advantage of the representation of the complex mixture of WSOC through model compounds is that they can be directly used in microphysical models for prediction of the aerosol hygroscopic properties and CCN ability starting from the chemical composition. In this respect, an application of the mixtures of model organic compounds evaluated in the present study is discussed in a companion paper (Mircea et al., 2005).

It is remarkable that despite the significant change in the relative strength of pyrogenic and biogenic sources from the dry to the wet period, the main chemical classes and functional groups of WSOC (and consequently the sets of model compounds) change only to a limited extent. This must be attributed to the fact that the decrease in the hydroxylated compounds and carboxylic acids of pyrogenic origin toward the end of the campaign was compensated by the increased contribution of analogous classes of compounds of biogenic nature. In this way, the pyrogenic and biogenic emissions provided a rather constant pool of very polar organic compounds in the submicron fraction of the aerosol throughout the dry-to-wet season transition. One consequence of this fact is the surprisingly similar cloud droplet nucleating ability (CCN ability) of the pyrogenic and biogenic aerosols over Amazonia (Andreae et al., 2004).

Acknowledgements. This work was carried out within the frame work of the Smoke, Aerosols, Clouds, Rainfall, and Climate (SMOCC) project, a European contribution to the Large-Scale Biosphere-Atmosphere Experiment in Amazonia (LBA). It was financially supported by the Environmental and Climate Program of the European Commission (contract No. EVK2-CT-2001-00110 SMOCC), the Max Planck Society (MPG), the Fundação de Amparo à Pesquisa do Estado de São Paulo, and the Conselho Nacional de Desenvolvimento Científico (Instituto do Milênio LBA). Research at ISAC was also supported by the Italian Ministry of Environment (Italy-USA Cooperation on Science and Technology of Climate Change) and by the Project FISR Modellistica Molecolare. Research at Ghent University and the University of Antwerp was also supported by the Belgian Federal Science
Policy Office through the project "Characterization and sources of carbonaceous atmospheric aerosols" (contracts EV/02/11A and EV/06/11B). We thank all members of the LBA-SMOCC and LBA-RACCI Science Teams for their support during the field campaign, especially A. C. Ribeiro, M. A. L. Moura, J. von Jouanne, L. Tarozzi, and J. Cafmeyer.

Edited by: T. Hoffmann

\section{References}

Andreae, M. O., Rosenfeld, D., Artaxo, P., Costa, A. A., Frank, G. P., Longo, K. M., and Silva-Dias, M. A. F.: Smoking rain clouds over the Amazon, Science, 303, 1337-1342, 2004.

Averett, R. C., Leenheer, J. A., McKnight, D. M., and Thorn, K. A. (Eds.): Humic substances in the Suwannee River, Georgia: Interaction, properties, and proposed structures, USGS Report 87-557, U.S. Geological Survey, Denver, CO, 1989.

Birch, M. E. and Cary, R. A.: Elemental carbon-based method for monitoring occupational exposures to particulate diesel exhaust, Aerosol Sci. Technol., 25, 221-241, 1996.

Chang, H., Herckes, P., and Collett Jr., J. L.: On the use of anion exchange chromatography for the characterization of water soluble organic carbon, Geophys. Res. Lett., 32, L01810, doi:10.1029/2004GL021322, 2005.

Chow, J. C., Watson, J. G., Crow, D., Lowenthal, D. H., and Merrifield, T.: Comparison of IMPROVE and NIOSH Carbon measurements, Aerosol. Sci. Technol., 34, 23-34, 2001.

Claeys, M., Graham, B., Vas, G., Wang, W., Vermeylen, R., Pashynska, V., Cafmeyer, J., Guyon, P., Andreae, M. O., Artaxo, P., and Maenhaut, W.: Formation of secondary organic aerosols through photooxidation of isoprene, Science, 303, 1173-1176, 2004a.

Claeys, M., Wang, W., Ion, A. C., Kourtchev, I., Gelencsér, A., and Maenhaut, W.: Formation of secondary organic aerosols from isoprene and its gas-phase oxidation products through reaction with hydrogen peroxide, Atmos. Environ., 38, 4093-4098, 2004b.

Decesari, S., Facchini, M. C., Fuzzi, S., and Tagliavini, E.: Characterization of water soluble organic compounds in atmospheric aerosol: A new approach, J. Geophys. Res., 105, 1481-1489, 2000.

Decesari, S., Moretti, F., Fuzzi, S., Facchini, M. C., and Tagliavini, E.: Comment on "On the use of anion exchange chromatography for the characterization of water soluble organic carbon" by Chang et al., Geophys. Res. Lett., 32, L24814, doi:10.1029/2005GL023826, 2005.

Eatough, D. J., Eatough, N. L., Pang, Y., Sizemore, S., Kirchstetter, T. W., Novakov, T., and Hobbs, P. V.: Semivolatile particulate organic material in southern Africa during SAFARI 2000, J. Geophys. Res., 108, 8479, doi:10.1029/2002JD002296, 2003.

Falkovich, A. H., Schkolnik, G., Ganor, E., and Rudich, Y.: Adsorption of organic compounds pertinent to urban environments onto mineral dust particles, J. Geophys. Res., 109, D02208, doi:10.1029/2003JD003919, 2004.

Falkovich, A. H., Graber, E. R., Schkolnik, G., Rudich, Y., Maenhaut, W., and Artaxo, P.: Low molecular weight organic acids in aerosol particles from Rondonia, Brazil, during the biomassburning, transition and wet periods, Atmos. Chem. Phys., 5, 781- 
797, 2005,

SRef-ID: 1680-7324/acp/2005-5-781.

Fuzzi, S., Decesari, S., Facchini, M. C., Matta, E., Mircea, M., and Tagliavini, E.: A simplified model of the water soluble organic component of atmospheric aerosols, Geophys. Res. Lett., 20, 4079-4082, 2001.

Gao, S., Hegg, D. A., Hobbs, P. V., Kirchstetter, T. W., Magi, B. I., and Sadilek, M.: Water-soluble organic components in aerosols associated with savanna fires in southern Africa: Identification, evolution, and distribution, J. Geophys. Res., 108, 8491, doi:10.1029/2002JD002324, 2003.

Graham, B., Mayol-Bracero, O. L., Guyon, P., Roberts, G., Decesari, S., Facchini, M. C., Artaxo, P., Maenhaut, W., Koll, P., and Andreae, M. O.: Water-soluble organic compounds in biomass burning aerosols over Amazonia. 1. Characterization by NMR and GC-MS, J. Geophys. Res., 107, 8047, doi:10,1029/2001JD000336, 2002.

Graham, B., Guyon, P., Taylor, P. E., Artaxo, P., Maenhaut, W., Glovsky, M. M., Flagan, R. C., and Andreae, M. O.: Organic compounds present in the natural Amazonian aerosol: Characterization by gas chromatography-mass spectrometry, J. Geophys. Res., 108(D24), 4766, doi:10.1029/2003JD003990, 2003.

Havránek, V., Maenhaut, W., Ducastel, G., and Hanssen, J. E.: Mass size distribution for atmospheric trace elements at the Zeppelin background station in Ny Alesund, Spitsbergen, Nucl. Instr. Meth. B, 109/110, 465-470, 1996.

Hoffer, A., Gelencsér, A., Blazsó, M., Guyon, P., Artaxo, P., and Andreae, M. O.: Chemical transformation in organic aerosol from biomass burning, Atmos. Chem. Phys. Discuss., 5, 80278054,2005

SRef-ID: 1680-7375/acpd/2005-5-8027.

Kawamoto, H., Murayama, M., and Saka, S.: Pyrolysis behavior of levoglucosan as an intermediate in cellulose pyrolysis: polymerization into polysaccharide as a key reaction to carbonized product formation, J. Wood. Sci., 49, 469-473, 2003.

Knicker, H., Almendros, G., Gonzales-Vila, F. J., Martin, F., and Ludemann, H. D.: ${ }^{13} \mathrm{C}$ and ${ }^{15} \mathrm{~N}-\mathrm{NMR}$ spectroscopic examination of the transformation of organic nitrogen in plant biomass during thermal treatment, Soil Biol. Biochem., 28, 1053-1060, 1996.

Kubátová, A., Vermeylen, R., Claeys, M., Cafmeyer, J., and Maenhaut, W.: Carbonaceous aerosols and particulate organic compounds in Gent, Belgium, during winter and summer of 1998, J. Aerosol Sci., 30, suppl. 1, S905-S906, 1999.

Kubátová, A., Vermeylen, R., Claeys, M., Cafmeyer, J., Maenhaut, W., Roberts, G., and Artaxo, P.: Carbonaceous aerosol characterization in the Amazon basin, Brasil: novel dicarboxylic acids and related compounds, Atmos. Environ., 34, 5037-5051, 2000.

Mayol-Bracero, O. L., Guyon, P., Graham, B., Roberts, G. C., Andreae, M. O., Decesari, S., Facchini, M. C., Fuzzi, S., and Artaxo, P.: Water-soluble organic compounds in biomass burning aerosols over Amazonia: 2. Apportionment of the chemical composition and importance of the polyacidic fraction, J. Geophys. Res., 107, 8091, doi:10.1029/2001JD000522, 2002a.

Mayol-Bracero, O. L., Gabriel, R., Andreae, M. O., Kirchstetter, T. W., Novakov, T., Ogren, J., Sheridan, P., and Streets, D. G.: Carbonaceous aerosols over the Indian Ocean during the Indian Ocean Experiment (INDOEX): Chemical characterization, optical properties and probable sources, J. Geophys. Res., 107, 8030,
doi:10.1029/2000JD000039, 2002b.

Mircea, M., Facchini, M. C., Decesari, S., Cavalli, F., Emblico, L., Fuzzi, S., Vestin, A., Rissler, J., Swietlicki, E., Frank, G., Andreae, M. O., Maenhaut, W., Rudich, Y., and Artaxo, P.: Importance of the organic aerosol fraction for modeling aerosol hygroscopic growth and activation: a case study in the Amazon Basin, Atmos. Chem. Phys., 5, 3111-3126, 2005,

SRef-ID: 1680-7324/acp/2005-5-3111.

Mochida, M. and Kawamura, K.: Hygroscopic properties of levoglucosan and related organic compounds characteristic to biomass burning aerosol particles, J. Geophys. Res., 109, D21202, doi:10.1029/2004JD004962, 2004.

Moens, L., Evans, R. J., Looker, M. J., and Nimlos, M. R.: A comparison of the Maillard reactivity of proline to other amino acids using pyrolysis-molecular beam mass spectrometry, Fuel, 83, 1433-1443, 2004.

Nolte, C., Schauer, J. J., Cass, G. R., and Simoneit, B. T.: Highly polar organic compounds present in wood smoke and in the ambient atmosphere, Environ. Sci. Technol., 35, 1912-1919, 2001.

Pashynska, V., Vermeylen, R., Vas, G., Maenhaut, W., and Claeys, M.: Development of a gas chromatography/ion trap mass spectrometry method for determination of levoglucosan and saccharidic compounds in atmospheric aerosols: Application to urban aerosols, J. Mass Spectrom., 37, 1249-1527, 2002.

Reid, J. S., Koppmann, R., Eck, T. F., and Eleuterio, D. P.: A review of biomass burning emissions, part II: Intensive physical properties of biomass burning particles, Atmos. Chem. Phys., 5, 799-825, 2005,

SRef-ID: 1680-7324/acp/2005-5-799.

Schkolnik, G., Falkovich, A. H., Rudich, Y., Maenhaut, W., and Artaxo, P.: A new analytical method for the determination of levoglucosan, polyhydroxy compounds and 2-methylerythrol and its application to smoke and rainwater samples, Environ. Sci. Technol., 39, 2744-2742 2005.

Schmid, H., Laskus, L., Abraham, H. J., Baltensperger, U., Lavanchy, V., Bizjak, M., Burba, P., Cachier, H., Crow, D., Chow, J., Gnauk, T., Even, A., ten Brink, H. M., Giesen, K.-P., Hitzenberger, R., Hueglin, C., Maenhaut, W., Pio, C., Carvalho, A., Putaud, J.-P., Toom-Sauntry, D., and Puxbaum, H.: Results of the carbon conference international aerosol carbon round robin test stage I, Atmos. Environ., 35, 2111-2121, 2001.

Shafidazeh, F.: The chemistry of pyrolysis and combustion, in: Chemistry of Solid Wood, edited by: Rowell, R., Advances in Chemistry Series 207, American Chemical Society, Washington D.C., 489-529, 1984.

Simoneit, B. R. T.: Biomass burning - a review of organic tracers for smoke from incomplete combustion, Appl. Geochem., 17, 129-162, 2002.

Simoneit, B. R. T., Elias, V. O., Kobayashi, M., Kawamura, K., Rushdi, A. I., Medeiros, P. M., Rogge, W. F., and Didyk, B. M.: Sugars-Dominant water-soluble organic components in soils and characterization as tracers in atmospheric particulate matter, Environ. Sci. Technol., 38, 5939-5949, 2004.

Souza, S. R., Vasconcellos, P. C., and Carvalho, L. R. F.: Low molecular weight carboxylic acids in an urban atmosphere: Winter measurements in Sao Paulo City, Brazil, Atmos. Environ. 33 , 2563-2574, 1999.

Svenningsson, B., Rissler, J., Swietlicki, E., Mircea, M., Bilde, M., Facchini, M. C., Decesari, S., Fuzzi, S., Zhou, J., Monster, J., 
and Rosenorn, T.: Hygroscopic growth and critical supersaturations for mixed aerosol particles of inorganic and organic compounds of atmospheric relevance, Atmos. Chem. Phys. Discuss., 5, 2833-2877, 2005,

SRef-ID: 1680-7375/acpd/2005-5-2833.

Tagliavini, E., Moretti, F., Decesari, S., Facchini, M. C., Fuzzi, S., and Maenhaut, W.: Functional group analysis by $\mathrm{H}$ $\mathrm{NMR} /$ chemical derivatization for the characterization of organic aerosol from the SMOCC field campaign, Atmos. Chem. Phys. Discuss., 5, 9447-9491, 2005,

SRef-ID: 1680-7375/acpd/2005-5-9447.

Wang, W., Kourtchev, I., Graham, B., Cafmeyer, J., Maenhaut, W., and Claeys, M.: Characterization of oxygenated derivatives of isoprene related to 2-methyltetrols in Amazonian aerosols using trimethylsilylation and gas chromatography/ion trap mass spectrometry, Rapid Commun. Mass Spectrom., 19, 1343-1351, 2005.
Wolfenbarger, J. K. and Seinfeld, J. H.: Inversion of aerosol size distribution data, J. Aerosol Sci., 21, 227-247, 1990.

Wurzler, S., Herrmann, H., Neusüß, C., Wiedensohler, A., Stratmann, F., Wilck, M., Trautmann, T., Andreae, M. O., Helas, G., Trentmann, J., Langmann, B., Graf, H., and Textor, C.: Impact of vegetation fires on the composition and circulation of the atmosphere: Introduction of the research project EFEU, J. Aerosol Sci., 32 (Suppl), 199-200, 2001.

Zdráhal, Z., Oliveira, J., Vermeylen, R., Claeys, M., and Maenhaut, W.: Improved method for quantifying levoglucosan and related monosaccharide anhydrides in atmospheric aerosols and application to samples from urban and tropical locations, Environ. Sci. Technol., 36, 747-753, 2002. 